\title{
Polymers as Advanced Materials for Desiccant Applications: 1988
}

\author{
A. W. Czanderna
}

H. H. Neidlinger

September 1990

Prepared under Task No. SB915001

Solar Energy Research Institute A Division of Midwest Research Institute

1617 Cole Boulevard

Golden, Colorado 80401-3393

Prepared for the

U.S. Department of Energy

Contract No. DE-AC02-83CH10093 


\section{NOTICE}

This report was prepared as an account of work sponsored by an agency of the United States government. Neither the United States government nor any agency thereof, nor any of their employees, makes any warranty, express or implied, or assumes any legal liability or responsibility for the accuracy, completeness, or usefulness of any information, apparatus, product, or process disclosed, or represents that its use would not infringe privately owned rights. Reference herein 10 any specific commercial product, process, or service by trade name, trademark, manufacturer, or otherwise does not necessarily constitute or imply its endorsement, recommendation, or favoring by the United States government or any agency thereof. The views and opinions of authors expressed herein do not necessarily state or reflect those of the United States government or any agency thereof.

Printed in the United States of America

Available from:

National Technical Information Service

U.S. Department of Commerce.

5285 Port Royal Road

Springfield, VA 22161

Price: Microfiche A01

Printed Copy A04

Codes are used for pricing all publications. The code is determined by the number of pages in the publication. Information pertaining to the pricing codes can be found in the current issue of the following publications which are generally available in most libraries: Energy Research Abstracts (ERA); Govern-. ment Reports Announcements and Index (GRA and I); Scientific and Technical Abstract Reports (STAR); and publication NTIS-PR-360 available from NTIS at the above address. 


\section{PREFACE}

In keeping with the national energy policy goal of fostering an adequate supply of energy at a reasonable cost, the U.S. Department of Energy (DOE) supports a variety of programs to promote a balanced and mixed energy resource system. The mission of the DOE Solar Building Research and Development Program is to support this goal by providing for the development of solar technology alternatives for the buildings sector. The goal of the program is to establish a proven technology base to allow industry to develop solar products and designs for buildings that are economically competitive and can contribute significantly to building energy supplies nationally. Toward this end, the program sponsors research activities related to increasing the efficiency, reducing the cost, and improving the long-term durability of passive and active solar systems for building water and space heating, cooling, and daylighting applications. These activities are conducted in four major areas: (1) Advanced Passive Solat Materials Research, (2) Collector Technology Research, (3) Cooling Systems Research, and (4) Systems Analysis and Applications Research.

Advanced Passive Solar Materials Research. This activity area includes work on new aperture materials for controlling solar heat gains and for enhancing the use of daylight for building interior lighting purposes. It also encompasses work on low-cost thermal storage materials that have high thermal storage capacity and can be integrated with conventional building elements, and work on materials and methods to transport thermal energy efficiently between any building exterior surface and the building interior by non-mechanical means.

Collector Technology Research. This activity area encompasses work on advanced low-to-medium temperature (up to $180^{\circ} \mathrm{F}$ useful operating temperature) flat-plate collectors for water and space heating applications, and mediumto-high temperature (up to $400^{\circ} \mathrm{F}$ useful operating temperature) evacuated tube/ concentrating collectors for space heating and cooling applications. The focus is on design innovations using new materials and fabrication techniques.

Cooling Systems Research. This activity area involves research on high performance dehumidifiers and chillers that can operate efficiently with the variable thermal output and delivery temperatures associated with solar collectors. It also includes work on advanced passive cooling techniques.

Systems Analysis and Applications Research. This activity area encompasses experimental testing, analysis, and evaluation for solar heating, cooling, and daylighting systems for residential and nonresidential buildings. This involves system integration studies; the development of design and analysis tools; and the establishment of overall cost, performance, and durability targets for various technology or system options.

This work relates to Cooling Systems Research for improving the performance of desiccant cooling systems (DCS) that process water vapor in an atmosphere to produce cooling. By identifying a next-generation, low-cost, advanced desiccant material, the cost of air-conditioning buildings can be lowered by improving the performance of DCS and by eliminating the need to add peak-load, electric-generating capacity. 
SEP

$\mathrm{PR}-3443$

This report documents the work accomplished during calendar year 1988 as a continuation of a subtask begun in 1985 in the Solar Desiccant Cooling Program. The work was carried out by H. H. Neidlinger, P. Gomez, Y. Shinto, M. Kiss, R. Login, and A. W. Czanderna. The authors emphasize that this is a progress report on the advanced desiccant materials research subtask, and therefore includes material not normally presented in a technical report.

A.W. Gauderua

A. W. Czandetna, Subtask Leader

iv 


\section{SUMMARY}

The technological objective of this work is to identify a next-generation, low-cost material with which solar energy or heat from another low-cost energy source can be used for regenerating the water vapor sorption activity of the desiccant. The scientific objective of this task is to determine how the desired sorption performance of advanced desiccant materials can be predicted by understanding the role of the materials modifications and their surface phenomena.

This research is concerned with solid materials used as desiccants for desiccant cooling systems (DCS) that process water vapor in an atmosphere to produce cooling. The purpose of the Advanced Desiccant Materials (ADM) project during 1988 was to prepare modifications of polystyrene sulfonic acid sodium salt (PSSASS), to synthesize a hydrogel, and to evaluate the sorption performance of these and similar commercially available polymeric materials for their potential application in solid commercial desiccant cooling systems (CDCS). An ADM can advance solar buildings technology not only by lowering the cost of CDCS to compete with conventional air-conditioning but also by eliminating the need for adding peak-load generating capacity by electric utilities.

In this report, background information is presented that includes an introduction to DCS and the role of the desiccant as a system component. The purpose, background, rationale, and long-term technical approach for studying ADM are reported including using polymers as $A D M$ and the key research issues concerning polymers. The experimental method for measuring water vapor sorption by desiccants is described for a quartz crystal microbalance (QCM).

The water vapor sorption performance criteria used for screening the modified polymers prepared this year include the water sorption capacity from $5 \%$ to $80 \%$ relative humidity (R.H.), isotherm shape, and rate of adsorption and desorption. These criteria are in addition to the key materials parameters for ranking potential ADM, which are also listed from a previous report. Since the isotherm shape is especially important based on work by others, the discussion of our results focuses considerable attention on improving isotherms from the linear behavior obtained for silica gel towards a Type 1 behavior. The procedures used for preparing the polymers for studies with the QCM are discussed in general and given specifically for the different types of polymers prepared.

Measurements are presented for the sorption performance of the modified polymeric ADM materials with the QCM. The data include sorption isotherms and qualitative evaluation of the sorption kinetics. PSSASS and sodium polystyrene sulfonate (SPSS), which are both commercially available, were used for our polymer modification studies. The SPSS studied is a specific commercially available form of PSSASS with a known percentage of sulfonation ( $90 \%$ ) as well as its molecular weight (MW). The SPSS studied to date has a narrower MW distribution than the PSSASS. From sorption capacity measurements of PSSASS and SPSS with different MW, results demonstrated that the isotherm shape depends on the MW. More favorable isotherm shapes are obtained for MW between 5,000 and 60,000, but the optimum MW has not been deduced. Outside this MW region, the isotherms become more linear below $60 \%$ R.H. Accordingly, the first modification has been to prepare polystyrene sulfonic acid (PSSA) using 
polystyrene (PS) with a MW of 6,000 and 50,000. These MW are available commercially. The second modification was to sulfonate the PS to the acid form, i.e., PSSA, and exchange the acid form with sodium ions to form PSSASS. The PSSAs were prepared with targeted sulfonic acid percentages of $20 \%, 40 \%, 60 \%$, and $80 \%$, which were then exchanged to form the corresponding PSSASS. The preliminary sorption data on these PSSASS indicate the isotherm shape is improved between $40 \%$ and $80 \%$ sulfonation, so again there is sensitivity to the polymer synthesis method. Further work is required to establish if the optimum isotherm shape can be obtained within these percentages of sulfonation.

The synthesis and characterization of one cross-linked acrylic hydrogel polymer are described in detail. This is a swelling polymer with the potential of sorbing water in excess of $10,000 \%$ of its own mass. The temperature dependence of the swelling ratio and other pertinent physical characteristics of acrylic hydrogel are presented and discussed. If a swelling polymer can be successfully introduced into an engineering configuration, the large capacity of uptake will be especially attractive if it also produces an optimum isotherm shape.

A Sartorius beam microbalance system for measuring water vapor sorption was installed and planned for use in early 1989 to characterize the modified or synthesized desiccant polymers. The quartz crystal microbalance data collection, storage, and retrieval system has been improved to permit making better water diffusivity measurements while maintaining its outstanding capability for characterizing the water sorption performance parameters of polymeric ADM.

Future activities for the project are addressed. The priority need for continuing to modify existing polymers and "molecularly engineering" the preparation of polymers to serve as an ideal desiccant are highlighted.

A summary of the project, which has been prepared for an industrial peer review panel, is included in Appendix $A$. The reader may find it helpful to read Appendix $A$ before plunging into the detail of the entire report. 
TABLE OF CONTENTS

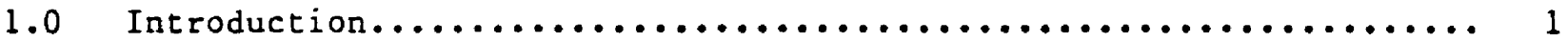

1.1 Objectives and Previous Reports..................... 1

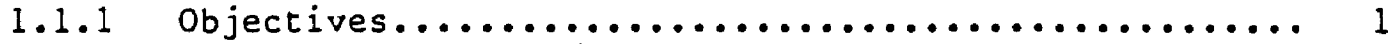

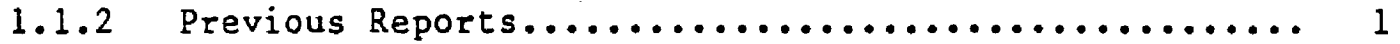

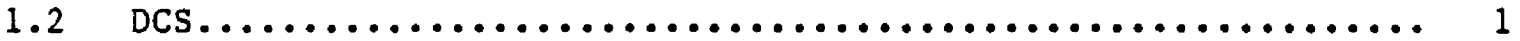

1.3 Purpose of ADM Research........................... 4

1.4 Polymers as ADM................................... 4

1.5 Goals/Specific objectives....................... 6

1.6 Technical Approach for Studying ADM.................. 7

2.0 Experimental Measurement of Water-Vapor Sorption by Polymers....... 10

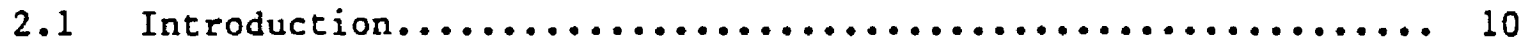

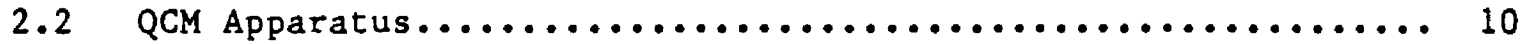

2.3 Procedures Used for Determining Isotherms............... 12

2.4 Kinetic and Cyclic Stability Studies................... 13

2.5 Procedure for Mounting Polymers on QCs for Sorption

Performance Measurements............................. 13

2.6 Installation of a Sartorius Microbalance................ 13

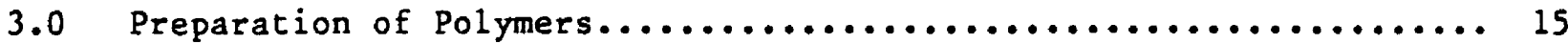

3.1 Commercially Available Polymers..................... 15

3.2 Preparation of Partially Sulfonated Polystyrenes........... 15

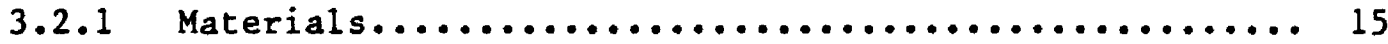

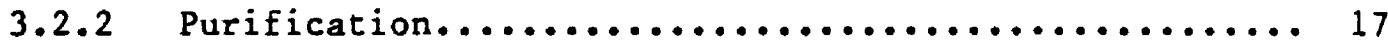

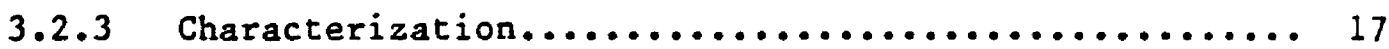

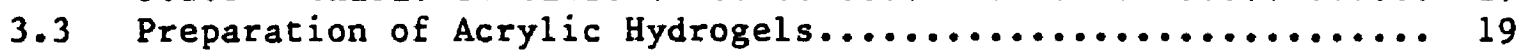

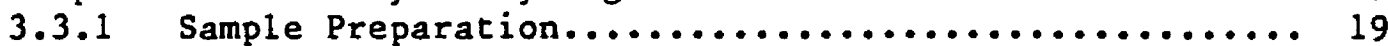

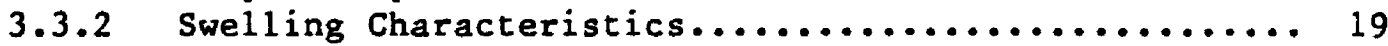

4.0 Experimental Results and Discussion of Sorption Measurements on

Different Polymers....................................

4.1 Results of Synthesis and Modification Efforts............ 20

4.1.1 Partially Sulfonated Polystyrenes................ 20

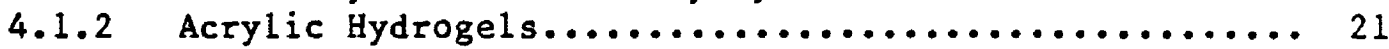

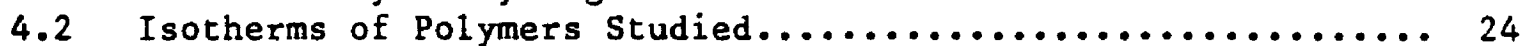

4.3 Isotherms Measured on Commercially Available Polymers of

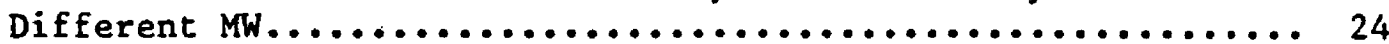

4.4 Isotherms for PSSASS with Different Percent Sulfonation..... 27

4.5 Other Influences on PSSASS Isotherms................. 28

4.5.1 Influence of Dialysis Purification............... 28

4.5.2 Influence of PSSASS Retained in the Organic Solvent.. 30

4.5.3 Influence of Cations (Counterions).............. 30

4.6 Conclusions................................... 31

5.0 Summary of Candidate ADM and Modified Polymers............... 32 
TABLE OF CONTENTS (Concluded)

6.0 Other Related Activities........................... 33

6.1 Isotherms of PSSASS Used by Cargocaire, Inc............ 33

6.2 I sotherms of PSSASS, PAAAS, and CSSS Studied at SERI's

Sorption Test Facility........................... 33

7.0 Future Activities................................ 34

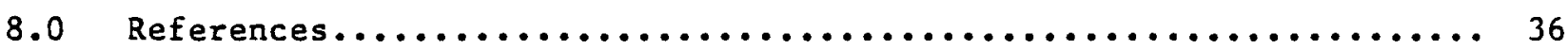

Appendix A Project Summary $1985-1988 \ldots \ldots \ldots \ldots \ldots \ldots \ldots \ldots \ldots \ldots \ldots$

Appendix B Advanced Desiccant Materials and Desiccant Cooling Systems:

Relationship and Background....................... 44

Appendix C Criteria for Identifying Potential and Candidate Advanced

Desiccant Materials............................... 48

Appendix D Desiccant Compositions for Desiccant Cooling Systems........ 50

Appendix E Quartz Crystal Microbalance Apparatus................. 51

Appendix E Kinetic and Cyclic Stability studies................. 54

Appendix G Additional Classes of Polymers Identified in 1987 as

Potential Advanced Desiccant Materials............... 56 


\section{LIST OF FIGURES}

$\underline{\text { Page }}$

1-1 Comparison of PSSASS and silica gel isotherms with Collier's Type 1 moderate; Type 2; 1 inear; and Type 3 moderate isotherms..... 3

2-1 Block diagram showing the principal components of. a QCM apparatus.. 11

2-2 Schematic of vacuum system for QCM apparatus................ 11

2-3 Block diagram illustrating arrangement of a combined QCM and SM apparatus..................................... 14

4-1 Equivalent extinction coefficients ( $\varepsilon$ eq.) of the sodium salt of partially sulfonated polystyrene in water at $25^{\circ} \mathrm{C}$ as a function of the degree of sulfonation $(\alpha) \ldots \ldots \ldots \ldots \ldots \ldots \ldots \ldots \ldots \ldots \ldots \ldots$

4-2 Temperature dependence of the swelling ratio $X$ for acrylic hydrogels...........................................

4-3 Comparison of a swollen gel (left) to a dry gel (right)......... 23

4-4 Water vapor adsorption isotherms at $22.1^{\circ} \mathrm{C}$ for National Starch

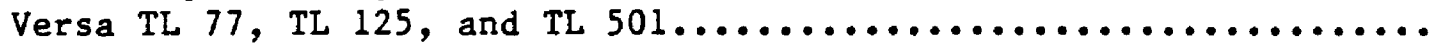

4-5 Water vapor adsorption isotherms at $22.1^{\circ} \mathrm{C}$ for different MW of SPSS. (The open triangles for MW of 66,100 and $210 \mu g$ of SPSS are for desorption and the solid triangles are for adsorption.).......

4-6 Water vapor adsorption isotherms at $22.1^{\circ} \mathrm{C}$ for SERI-prepared PSSASS (MW 6,000) for different targeted percent sulfonation......

4-7 Water vapor adsorption isotherms at $22.1^{\circ} \mathrm{C}$ for SERI-prepared PSSASS (MW 6,000; unpurified) with different percent sulfonation compared with SPSS $(90 \%, M W=66,100) \ldots \ldots \ldots \ldots \ldots \ldots \ldots \ldots \ldots$

4-8 Water vapor adsorption isotherms at $22.1^{\circ} \mathrm{C}$ for SERI-prepared PSSASS (NW 6,000; purified) with different percent sulfonation compared with SPSS $(100 \%$ Aldrich Chemical $) .. \ldots \ldots \ldots \ldots \ldots \ldots \ldots$

4-9 Water vapor adsorption isotherms at $22.1^{\circ} \mathrm{C}$ for SERI-prepared PSSASS (MW 50,000; purified) for different percent sulfonation.....

4-10 Water vapor adsorption isotherms at $22.1^{\circ} \mathrm{C}$ for SERI-prepared PSSASS soluble in DCE for targeted sulfonations of $60 \%$ and $80 \%$....

4-11 Water vapor adsorption isotherms at $22.1^{\circ} \mathrm{C}$ for SERI-prepared PSSA (MW 6,000; unpurified) for targeted sulfonations of $40 \%, 60 \%$,

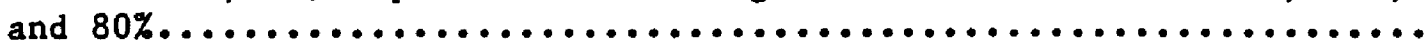

6-1 Water vapor adsorption isotherms at $22.1^{\circ} \mathrm{C}$ for commercial preparations of PAAAS and CSSS studied at the SERI sorption Test Facility. 


\section{LIST OF TABLES}

$\underline{\text { Page }}$

3-1 Commercially Available Polymers Characterized for Water-Vapor Sorption Performance................................ 16

3-2 Listing of All Preparations of PSSASS................... 18

3-3 All Preparations of Acrylic Hydrogels...................... 19

4-1 Specific and Equivalent Extinctions of the Sodium Salt of Partially Sulfonated Polystyrene (in Water at $25^{\circ} \mathrm{C}$ )........... 21

4-2 Summary of Isotherm Data for Polymers Studied as Potential ADM..... 26 


\section{ACRONYMS}

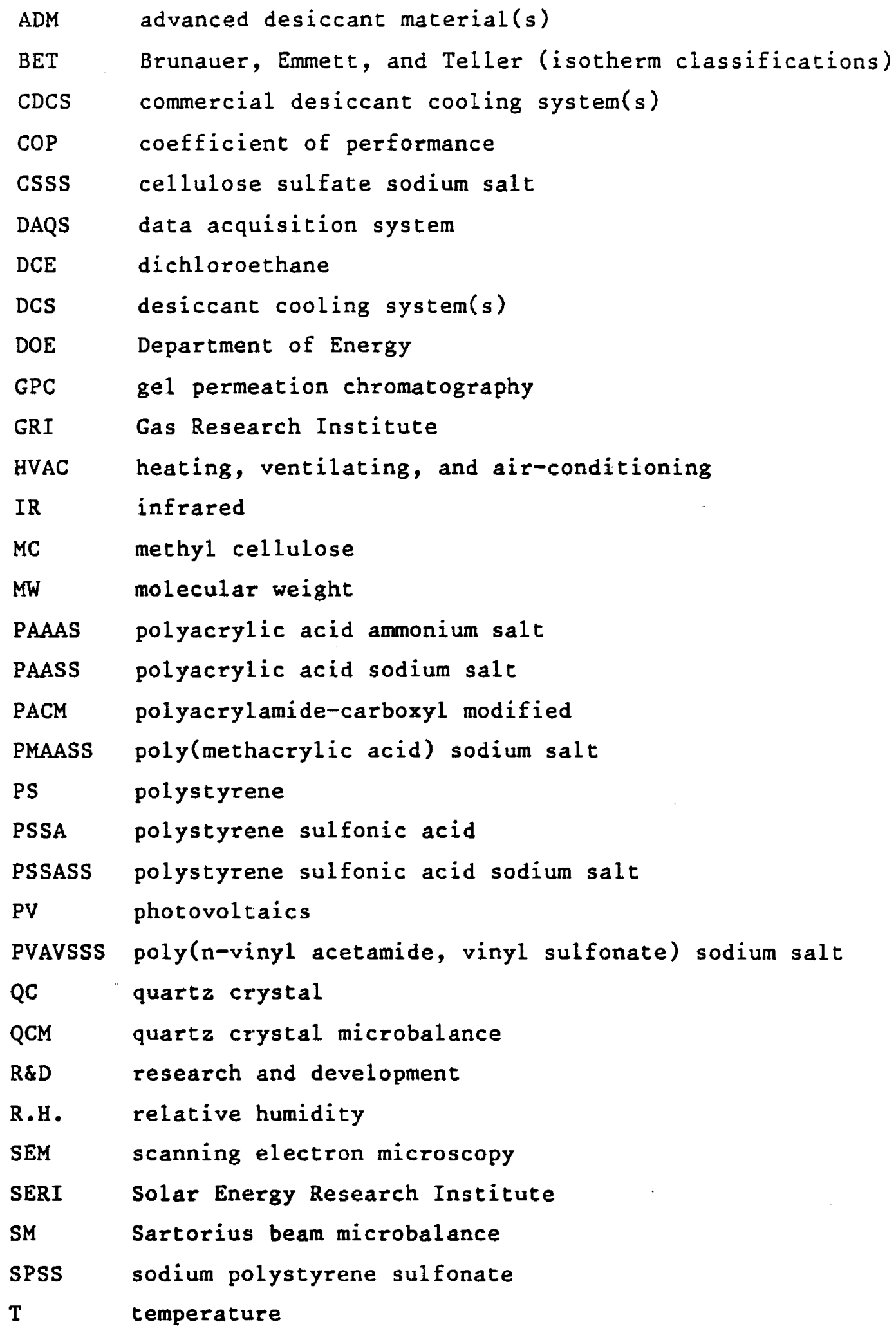




\subsection{INTRODUCTION}

\subsection{Objectives and Previous Reports}

\subsubsection{Objectives}

The technological objective of this work is to identify a next-generation, low-cost material with which solar energy or heat from another low-cost energy source can be used for regenerating the water-vapor sorption activity of the desiccant.

The scientific objective is to determine how the desired sorption performance of advanced desiccant materials (ADM) can be predicted by understanding the role of the materials modifications and their surface phenomena.

\subsubsection{Previous Reports}

In our first annual report, we presented background information that included a brief introduction to desiccant cooling systems (DCS) and the role of the desiccant as a system component (Czanderna and Thomas 1986). In calendar year 1986, we prepared two papers for publication: "Polymers: Options as Advanced Desiccant Materials" (Czanderna and Thomas 1989), and "A Quartz Crystal Microbalance Apparatus for Water Sorption .by Polymers" (Czanderna and Thomas 1987b). In calendar year 1987, we completed our second annual report, Advanced Desiccant Materials Research-1986 (Czanderna and Thomas 1987a). In 1988, we completed our third annual report entitled "Polymers as Advanced Materials for Desiccant Applications: 1987" (Czanderna 1988). Since many readers might not have a complete set of these previous reports, required information is integrated in this report, either directly in the main body of the report or into an appendix. Where detail about other aspects of the previous work (e.g., experimental apparatus, design, and construction) is not crucial to understanding the results and discussion of the progress made in calendar year 1988, which is the subject of this report, the reader is referred to the appropriate previous documents.

\subsection{DCS}

DCS research is concerned with solid materials used as desiccants for systems that process atmospheric water vapor to produce net cooling. Since mass transfer occurs between the system and its environment, these systems are commonly referred to as "open-cycle" systems (Collier, Barlow, and Arnold 1982). All of these systems use a liquid or solid material called a desiccant to remove water vapor from the air either by adsorption onto or into a solid desiccant or by absorption into the liquid desiccants. This report will focus on the solid-type desiccant system although the reader will recognize the opportunity using liquid-based systems.

Systems with solid desiccants are currently used in industrial air-drying applications (Bry-Air and Cargocaire 1984) and in DCS. These systems use a desiccant-laden wheel in which air may flow in the axial direction only. The solid desiccant (typically silica gel or lithium chloride, or both) is mounted onto a wheel and the air to be dried flows through one side of the wheel, while the desiccant on the other side of the wheel is being dried by an externally heated air stream. These two airstreams are kept physically 
separated to maintain the distinctly separate functions of air dehumidification and desiccant regeneration. The historical development that led to present commercial systems has been summarized elsewhere (Collier, Barlow, and Arnold 1982).

The commercial systems are primarily intended for specialized applications that require dehumidifying air and usually do not produce a significant net cooling. There are important differences in design philosophy between solarregenerated desiccant cooling systems and commercial desiccant dehumidifiers. The most important difference involves the thermal and electrical coefficients of performance (COP). (COP is discussed and defined in Collier, Barlow, and Arnold 1982.) For many years, commercial desiccant dehumidifier manufacturers have chosen markets in which vapor-compression equipment cannot compete (i.e., applications where extremely dry air is required or where latent cooling loads are high). The energy requirements to achieve these conditions have not been a major concern, and, as a consequence, the desiccant dehumidifiers often have very low thermal and electrical COPs. Recently, dehumidifier manufacturers, who have been funded by the Gas Research Institute (GRI), have entered the supermarket heating, ventilating, and air-conditioning (HVAC) business where prospects appear attractive.

Commercial, solar-regenerated DCS must compete with vapor compression as well as all other space-cooling technologies, so electrical and thermal COPs as well as the initial capital costs are primary concerns. From thermodynamic analyses of desiccant cooling cycles, we know that the adsorption characteristics of the desiccant can have a large influence on the cooling capacity and COP of the cycle (Collier, Barlow, and Arnold 1982, and Jurinak 1982). This effect was quantified in a recent computer parametric systems analysis study (Collier, Cale, and Lavan 1986). While this study assumed a regeneration temperature of $160^{\circ} \mathrm{C}$, the conclusions about an "ideal" desiccant are also applicable for solar regeneration temperatures of $60^{\circ}$ to $95^{\circ} \mathrm{C}$. The researchers also concluded that if an "ideal" desiccant can be identified, the thermal COP of a DCS can be improved from 0.85 to 1.05 , which can now be obtained with silica gel, up to a minimum of 1.3 to 1.4 or close to the theoretical maximum. " $I d e a l "$ is in quotation marks because there are properties of an ideal desiccant that were not included in their study. Isotherm shapes are discussed below and are very important for our work.) At the same time, the cubic feet per minute per ton ( $\mathrm{cfm} / \mathrm{ton}$ ) can be reduced from a range of 310 to 400 for silica gel to a range of 200 to 250 for an "ideal" desiccant. The reduction in $\mathrm{cfm} / \mathrm{ton}$ must not be overlooked since this factor can reduce the physical size of commercial DCS while keeping electrical parasitic consumption low. If both these factors were achieved, DCS could be cost-competitive with other current air-conditioning systems; this is not possible for silica gel (Collier, Cale, and Lavan, 1986).

For the computer parametric analysis, Collier, Cale, and Lavan (1986) chose five types of isotherms that they designated as Brunauer, Emmett, and Teller (BET) Type 1 extreme; Type 1 moderate; linear; Type 3 moderate; and Type 3 extreme. The following isotherms are illustrated in Figure 1-1: Type 1 moderate; BET Type 2; Type 3 moderate; and linear isotherms used for the study. The Type 1 moderate isotherm is the optimum shape for the "ideal" desiccant, and the sorption should follow this isotherm between $5 \%$ and $60 \%$ R.H. for best results (Collier 1987). We have also plotted the isotherm for a silica gel, where the $37 \%$ water uptake at $100 \%$ relative humidity (R.H.) 


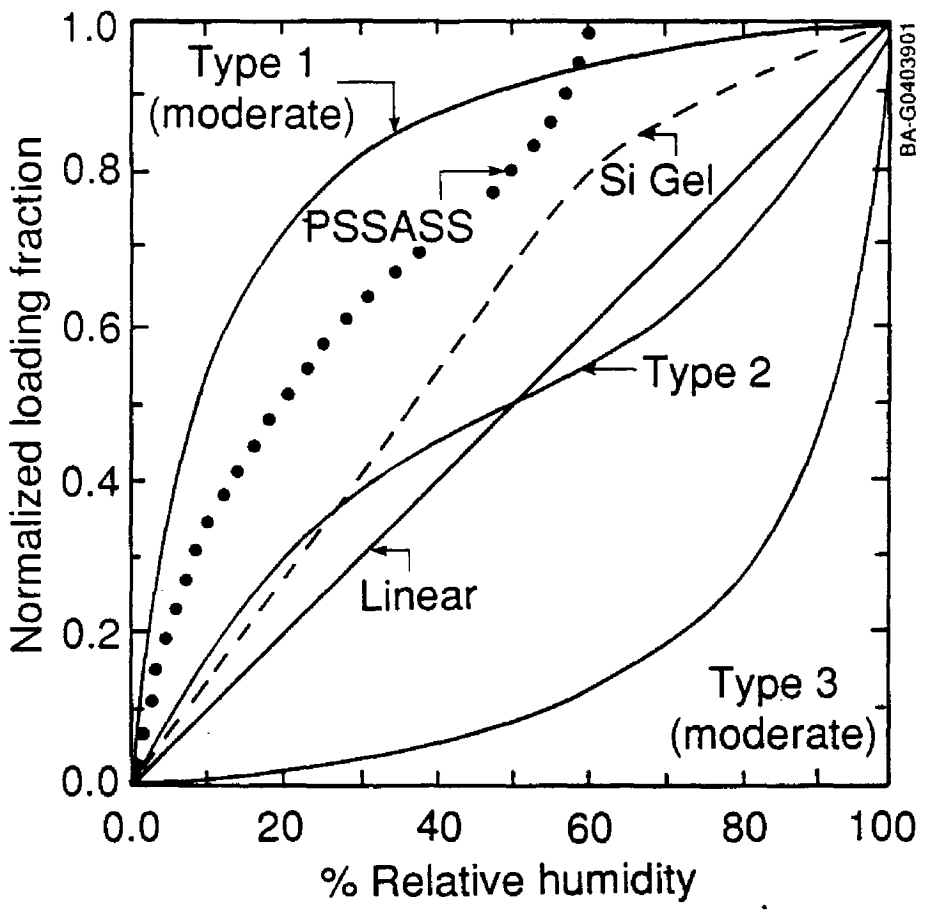

Figure 1-1. Comparison of PSSASS and silica gel isotherms with Collier's Type 1 moderate; Type 2; linear; and Type 3 moderate isotherms

is normalized to a loading fraction of 1.0 and part of the isotherm for polystyrene sulfonic acid sodium salt (PSSASS), where the $40 \%$ water uptake at $60 \%$ R.H. is normalized to a loading fraction of 1.0 . As is seen, PSSASS is close to the Type 1 moderate isotherm shape as normalized, which is part of the reason we chose to emphasize modification of this polymer in 1988. At low R.H. of water vapor, the BET Type 2 isotherm has a knee that becomes more pronounced as the BET $c$ value increases to values from 50 to 200 or more. [For a particular isotherm, $c$ is a constant in the two-parameter, BET equation (Adamson, 1982)]. Larger $c$ values correspond to stronger interactions between the gas and the solid. With $c$ values below 10 (weaker interactions), the isotherms become linear and then Type 3 (moderate and then extreme). Thus, an objective of modifying polymers with Type 2 behavior is to increase the watervapor solid interactions to sharpen the knee to track the Type 1 moderate shape. Interactions that are too strong produce a Type 1 extreme isotherm, which has nearly all of its uptake or loading at low R.H. Desiccants with Type 1 extreme isotherms are more difficult to regenerate, which is why the Type 1 moderate isotherm is favored (Collier, Cale, and Lavan 1986).

In CDCS wheel geometries, silica gel and lithium chloride are now the most widely used desiccant materials. Extensive optimization studies of the engineering design of DCS units have been carried out using silica gel (Barlow 1982; Jurinak 1982; Pesaran and Mills 1984; Schlepp and Schultz 1984; Pesaran et al. 1986). Models in systems analysis studies for estimating the achievable thermal and electrical COP also use the properties of silica gel since they have been documented extensively over several decades (Parent 1985). Since the water sorption properties of the desiccant are crucial to the performance of any system, this desiccant materials research effort was initiated to search for and measure the properties of materials that could not only 
outperform silica gel as a desiccant but also approach the "ideal" desiccant material in its sorption performance. In addition, manufacturing methods with new materials could have a profound impact on reducing the dehumidifier cost.

\subsection{Purpose of ADM Research}

One purpose for performing long-range research on materials is to secure an understanding of the behavior of low-cost, high-performance technological materials, with a goal of extending the lifetime of these materials, or to identify new materials that will offer new options for components used in operating systems. The cost-effective deployment of DCS is currently limited by the sorption performance, durability, and life-cycle cost of the inorganic materials used. Long-term materials research is needed that focuses on improving the properties of $\mathrm{ADM}$ and on identifying the reasons for degradation of their sorption performance.

The purpose of ADM research and development (R\&D) is to provide new materials options for DCS. The ultimate purpose is to identify materials with optimal performance in the temperature range used in a DCS in which the sorption activity of the desiccant can be routinely regenerated with an appropriate energy source. The performance of these materials can be ranked as compared to the performance of silica gel, which can be used as the standard for comparison. The life-cycle cost (i.e., initial cost, performance, and durability) has a direct relationship to the cost-effective deployment of any regenerative DCS. Identification of materials with extended lifetimes, enhanced reliability, and sustained desirable sorption properties for use in DCS can be anticipated from a sustained R\&D effort. Thus, an ADM can advance solar buildings technology not only by lowering the cost of commercial solid desiccant cooling systems (CDCS) to compete with conventional air-conditioning but also by eliminating the need for adding peak-load generating capacity by electric utilities.

\subsection{Polymers as ADM}

The relationship of desiccant materials to DCS and background information about studies of ADM are summarized in Appendix B. Polymers must satisfy the same general criteria as any desiccant material. They must have a favorable performance/cost ratio, provide satisfactory performance, and have costeffective 1 ifetimes; widely available materials need to be certified, modified, or, in some cases, developed specifically for use in DCS. Some of the important parameters for the water solid-desiccant-material system include isotherm shape, sorption capacity, heat of sorption, rate of sorption at or near the desiccant bed temperature $\left(25^{\circ}\right.$ to $\left.55^{\circ} \mathrm{C}\right)$, rate of desorption at an elevated temperature, physical and chemical stability of the desiccant, and cyclic repeatability of the sorption amount and rates. Some important conclusions and recommendations on these parameters were reached in the recent modeling study for regeneration at $160^{\circ} \mathrm{C}$ (Collier, Cale, and Lavan 1986), but the possibility of identifying new materials with optimal properties was not considered.

From our literature search (Czanderna and Thomas 1986), we identified both inorganic and organic (i.e., polymeric) materials as potential candidate ADM for use in DCS. To focus our research, we initially selected 21 commercially available polymeric materials for further study. These have been listed in 
previous reports (Czanderna and Thomas 1986; Appendices A and B of Czanderna 1988). The process used to narrow the 1 ist of over 300 commercially available polymers to those summarized has also been reported (Czanderna and Thomas 1989, Section 3.0). We identified several additional polymers as our studies progressed.

By considering the available polymeric desiccants, we note the following:

- Polymers have the potential of being modified so that sorption isotherms of both the desired shape and heats of adsorption of about $10.8 \mathrm{kcal} / \mathrm{mol}$ are obtained.

- Polymers have been identified that sorb water from $5 \%$ to more than $80 \%$ of their own weight and have the potential of sorbing $10,000 \%$ of their own weight.

- Polymers have the potential for being readily fabricated into shapes required for DCS, e.g., a honeycomb structure $10 \times 0.04 \times 0.06$ in. when a "desiccant polymer" is not a structural material, it may be grafted onto a structural polymer.

- Polymer structures have the potential of being synthesized to provide high diffusivities of water vapor through the material.

- Polymers have the potential for being regenerated at temperatures below $80^{\circ} \mathrm{C}$ for thermally desorbing water.

- Polymers have the potential for maintaining long-term stability through thousands of sorption-desorption cycles.

- Commercial polymers are available at less than $\$ 2 / 1 b$, or comparable to the cost of commercial-grade silica gel.

Accordingly, polymeric materials could not only serve as both the desiccant and the support structure in a desiccant wheel, but could also be replaced easily and inexpensively if their water sorption capacity degrades. The initial need of this research was to characterize the water sorption performance of polymeric materials that could serve in an economically competitive DCS. The current and future needs include modifying candidate polymeric materials identified in prior work and synthesizing new polymeric materials that have the desired water-vapor sorption performance properties.

The key technical questions in seeking candidate polymers for DCS are:

- Will any commercially available polymer have the properties required for use in a DCS? Several promising candidate materials have been identified, but none have optimum or "ideal" properties.

- Can the polymeric material be modified to improve performance properties such as isotherm shape, heat of adsorption, regeneration temperature, cyclic stability, and diffusivity? The authors are convinced that this question will be answered affirmatively, and recent progress in making modified PSSASS for supporting our conviction is the main content of this report.

- If commercially available polymers are not suitable, can 1aboratoryprepared polymers be synthesized with suitable sorption, desorption, and stability properties? 
- Do the performance properties depend on the sample size and configuration (e.g., $0.1 \mathrm{mg}$ [quartz crystal microbalance (QCM)], $100 \mathrm{mg}$ (beam microbalance), and SERI test-loop scale and configuration)?

- What impurities in the airstream cause a loss of sorption performance in candidate polymers?

- Are there other degradation processes that cause a candidate polymer to lose sorption performance?

We have initiated work in the past four years that provides a rapid QCM method for evaluating the performance properties of ADM with an emphasis on polymers. These include measuring sorption isotherms, sorption and desorption kinetics, and the cyclic stability of advanced desiccant materials. From the past studies, we narrowed the commercially available polymers to nine potential candidates for further study and/or modification:

- polystyrene sulfonic acid sodium salt

- sodium polystyrene sulfonate [molecular weight (MW) 4000 to 66,000 ](SPSS)

- polyacrylamide-carboxyl modified

(PACM)

- polyacrylic acid ammonium salt

(PAAAS)

- poly(methacrylic acid) sodium salt

(PMAASS)

- poly(n-vinylacetamide, vinyl sulfonate) sodium salt

(PVAVSSS)

- polyacrylic acid sodium salt

- cellulose sulfate sodium salt

- methyl cellulose

During 1988, our efforts were focused on modifying PSSASS and using commercial formulations of SPSS with widely varying MW. Both of these polymers are structurally the same (as discussed in section 3.0). In the future, additional polymers need to be studied that are modifications of those commercially available or synthesized specifically to serve as an ideal desiccant. Eventually, those polymers with the best properties will be subjected to simulated use conditions, and cause for any performance losses will be identified.

\subsection{Goals/Specific Objectives}

The long-range goal of this research has been developed for providing scientific understanding and information about new desiccant materials and the possibilities for physical and chemical modifications of the adsorbents to optimize their properties. The ultimate goal of this research is to understand the interactions between water vapor and candidate desiccant materials that control the sorption capacity of the material, the kinetics of sorption and desorption, and the stability of these parameters during repeated cycling.

The specific objectives of this multiyear task are: (1) to determine the feasibility for using polymeric materials and chemically modified candidate materials as desiccants; (2) to determine the effect of chemically or physically modified desiccant surfaces on the sorption capacity, the heat of sorption, and the sorption kinetics; (3) to determine if fundamental water vaporsolid interactions limit the stability of naturally occurring and chemically 
modified candidate desiccant materials; and (4) to study the topographical and compositional changes at or near the water vapor-solid interface of desiccant materials resulting from adsorption/desorption cycles between $25^{\circ} \mathrm{C}$ and a higher temperature. When the objectives are met, we will sufficiently understand the phenomena that are important to improving the performance, selecting materials, and extending the durability of materials for DCS. The research will also provide mechanistic insights into the molecular processes that underpin the potential for predictive lifetime behavior of desiccant beds used in DCS.

\subsection{Technical Approach for Studying ADM}

The key technical questions were used to formulate our technical approach. The multiyear technical approach for studying the water-vapor sorption by potential materials for use in regenerative DCS consists of conducting experimental work and interpreting the data; thus, the necessary understanding of the reversible and irreversible processes that take place can be obtained. The following variables and processes are particularly relevant for experimental research on desiccant materials.

To accomplish the goals and objectives of this research, the technical approach for this project has been and will be to perform the following:

(1) Identify, select, rank, and prepare potential ADM for, study;

(2) Modify polymers and inorganic materials to improve their sorption performance and synthesize new polymeric materials that are "molecularly engineered" to function as an "ideal" ADM;

(3) Identify the performance criteria of ADM including sorption performance and durability;

(4) Identify the necessary measurements for characterizing the water-vapor sorption performance of potential ADM;

(5) Design, purchase, construct, install, and use experimental apparatus necessary for characterizing the sorption performance and establishing the durability of ADM;

(6) Measure the sorption performance and determine relevant physical parameters of potential ADM to establish which materials are candidate ADM based on the criteria in (3) above;

(7) Determine the repeatability of the sorption performance of candidate ADM from 1, 2, 3, 4, and 6 above as a function of sorption-desorption cycles at time intervals corresponding to DCS and at regeneration temperatures planned for use in DCS;

(8) Determine the effect of chemical modification of ADM and ADM surfaces on the sorption performance;

(9) Conduct fundamental scientific investigations to understand the interplay among composition, bonding, topography, surface area, pore volume, pore size distribution, morphology, and their changes during cycling and use in real environments; 
(10) Perform analytical and theoretical work, as needed, to assess the opportunities and limitations of candidate ADM for use in the engineering configurations of contemporary DCS;

(11) Cooperate with others performing desiccant research and development to expedite the testing of candidate ADM in engineering, configurations; and

Prepare reports and publications, and make presentations to disseminate the results of the work.

The broad sequence of the research has been to perform a literature search of the sorption properties of candidate materials (Czanderna and Thomas 1986), to assist in developing the analytical expressions for modeling the ideal desiccant for water vapor, and then to carry out the experimental work. For the last, the inorganic and organic solids of interest for potential application have been or are being chosen, prepared, and studied.

Two principal activities were addressed during 1985: (1) identifying candidate materials for study, and (2) constructing a QCM sorption apparatus. For the first activity, we completed a literature search, identified polymeric and inorganic materials as potential advanced desiccants, conducted a critical analysis of the literature, and ranked the materials for study. We also developed in detail the opportunities for using polymeric materials as ADM. We identified the key materials parameters for ranking potential ADM, and ranked all identified materials of over 300 possibilities.

For the second activity, we first identified microgravimetric, compositional surface analytical, infrared spectroscopic, scanning electron microscopic, and thermal gravimetric measurements as the minimum number of techniques necessary for studying desiccant materials and understanding their morphological and surface properties. Then, we designed, purchased, assembled, constructed, installed, and initiated use of a QCM for characterizing the sorption performance of organic (polymeric) and inorganic materials. The results for identifying the candidate materials and a description of the QCM have been fully documented (Czanderna and Thomas 1986, Section 2.0). The results for the second activity were also given (Czanderna and Thomas 1986, Section 3.0).

During 1986, we concentrated on two activities: (1) improving the operation of the QCM that was assembled in 1985, with an ultimate goal of fully automatic data collection of sorption isotherms and kinetics; and (2) obtaining data on several of the 21 potential candidate polymers to initiate our process of narrowing these to candidate status. For the first activity, we achieved an acceptable level of semiautomatic operation of the QCM, but could not obtain complete automation because of funding limitations. For the second activity, we obtained data on three polymers with widely varying sorption capacities. The details for both activities have also been summarized by Czanderna and Thomas $(1987 a, 1987 \mathrm{~b})$. In a related task at the Solar Energy Research Institute (SERI), we demonstrated that surface compositional analysis using $X$-ray photoelectron spectroscopy and infrared spectroscopy will be useful for securing both fundamental and technological information about both present and advanced desiccant materials (Pesaran et al. 1986).

During 1987, we concentrated nearly all of our efforts on measuring the sorption performance of more than 23 potential candidate, commercially available, polymeric ADM. with the QCM. The measurements include determining sorption 
isotherms, rate of adsorption and desorption at each pressure increment or decrement, cyclic stability, and qualitative evaluations of permeation rates. We also identified the water-vapor sorption performance criteria (Appendix C) for narrowing the potential ADM to a few candidate ADM, where the sorption performance includes the sorption capacity from $5 \%$ to $80 \%$ R.H., isotherm shape, rate of adsorption and desorption, and cyclic stability of the $A D M$ in water-vapor. We used this criteria to narrow the number of polymeric materials to nine candidate ADM. In addition, we designed a Sartorius beam microbalance system (SM) for use on the project and designed an experimental procedure for an existing thermal gravimetric apparatus for studying the cyclic stability of ADM in humid air. We also initiated cyclic stability studies of several candidate polymeric ADM and established that nine polymers remained as serious candidate ADM.

During 1988, a publication (Czanderna 1988) and a patent application (Appendix D) were completed that give details on all prior work on this task. PSSASS and SPSS, which are both commercially available, were used for our polymer modification studies. The SPSS studied to date has a narrower MW distribution than the PSSASS. From sorption capacity measurements of PSSASS and SPSS with different MW, we demonstrated that the isotherm shape depends on the MW. The best isotherm shapes are obtained for MW between 5000 to 66,100, but the optimum MW has not been deduced. Outside this MW region, the isotherms become more linear below $60 \%$ R.H. Accordingly, the first modification has been to use polystyrene (PS) with a MW of 6,000 or 50,000, which are available commercially.

The second modification was to sulfonate the PS to the acid form [i.e., polystyrene sulfonic acid (PSSA)], and exchange the acid form with sodium ions to form PSSASS. The PSSA polymers were prepared with targeted sulfonic acid percentages of $20 \%, 40 \%, 60 \%$, and $80 \%$, which were then exchanged to form the corresponding PSSASS. The preliminary sorption data on these PSSASS indicate improved isotherms are obtained between $40 \%$ and $80 \%$ sulfonation, so again there is sensitivity to the polymer synthesis method. The commercially available SPSS is $90 \%$ sulfonated. Further work is required to establish if the optimum isotherm shape can be obtained within these sulfonation percentages.

A third modification was initiated in which PSSA was exchanged with lithium ions. This third modification may have had the most dramatic influence on the isotherm shape. Furthermore, four cross-1inked hydrogel polymers were synthesized. These are swelling polymers with the potential of sorbing water in excess of $10,000 \%$ of their own mass. If a swelling polymer can be successfully used in an engineering configuration, the large capacity uptake will be especially attractive if it also produces an optimum isotherm shape.

An SM system for measuring water vapor sorption was installed and will also be used to characterize the modified or synthesized desiccant polymers when it becomes operable. The QCM data collection, storage, and retrieval system has been improved to permit making better water diffusivity measurements while maintaining its outstanding capability for characterizing the water-sorption performance parameters of polymeric ADM. In collaboration with the other SERI tasks, an initial calculation of the diffusivity has been made for results on one polymer. With the new equipment, calculations can be extended to other candidate or promising polymers in FY 1989 and beyond. 


\subsection{EXPERIMENTAL MEASUREMENT OF WATER-VAPOR SORPTION BY POLYMERS}

\subsection{Introduction}

The experimental apparatus for measuring the water-vapor sorption by a solid is conceptually simple. An arrangement is needed where a solid can be surrounded by pure water vapor (or a partial pressure of water in the ambient atmosphere) and the number of water molecules that bond to the solid can be measured. A vacuum system can be used to control the gas (vapor) pressure over the solid. There are three basic methods for measuring directly the rate of gas adsorption and the equilibrium amount of vapor adsorbed by a solid: gravimetric, volumetric, and radiotracer. The last is excluded since it would require tritiated water and offers no obvious advantages over gravimetric techniques. Gravimetric techniques have many advantages over volumetric techniques (Gregg and Sing 1982; Czanderna and Wolsky 1980), especially for watervapor sorption studies. Water is one of the most difficult vapors to work with for analysis when using vacuum systems, but the determination of adsorption isotherms and the rate of adsorption and desorption of water can be carried out routinely with gravimetric techniques.

\subsection{QGM Apparatus}

of the available gravimetric techniques, the beam balance and the QCM are the two best choices when the advantages and 1 imitations of all microbalances are considered (Czanderna and Wolsky 1980). We chose to use a QCM for our initial studies because of the commercial availability of QCMs and their ease of use for studying the sorption of water by materials at or near $25^{\circ} \mathrm{C}$ ( $L u$ and Czanderna 1984). The experimental system, which is shown schematically in Figure 2-1, consists of a vacuum system, a residual gas analyzer, a QCM system with five quartz crystal (QC) sensors, and a temperature bath for the QCM. These components and their operation have been described in detail (Czanderna and Thomas 1986) and are summarized in Appendix E.

During 1988, a new data acquisition system (DAQS) was acquired to replace the failing MacSym 2 computer and printer used to obtain the mass data from the QCM and the temperature and pressure data. The DAQS reads, stores, and plots the data for visual observation from the five QCs in the QCM system every $2 \mathrm{~s}$ as well as performing the same function for the pressure, bath temperature, room temperature, and the temperature of two of the crystal holders. The DAQS was installed on November 28,1988 , so our present experience with it is not sufficient to comment further on its capabilities. However, it is designed to be vastly superior for obtaining, displaying, and plotting kinetic data during adsorption and desorption. These data will now be stored every 2 s rather than every $30 \mathrm{~s}$, which was the limit for the MacSym 2 printer combination used from late 1985 through June 1988. (The repair costs for the obsolete MacSym 2 were prohibitive compared with the purchase of the DAQS.)

For isotherm measurements, the polymers were mounted onto QCs as described in detail (Czanderna 1988, Section 4.2). After determining the polymer mass, the QCs were mounted onto a QC holder. For the vacuum measurements, the QC holder is an integral part of a vacuum system apparatus as shown in Figure 2-2. The essential components of this holder include a 2.75-in. stainless steel Conflat vacuum flange with feedthroughs for a thermocouple, cooling water, and the electrical leads needed for operating the oscillator. The essential 


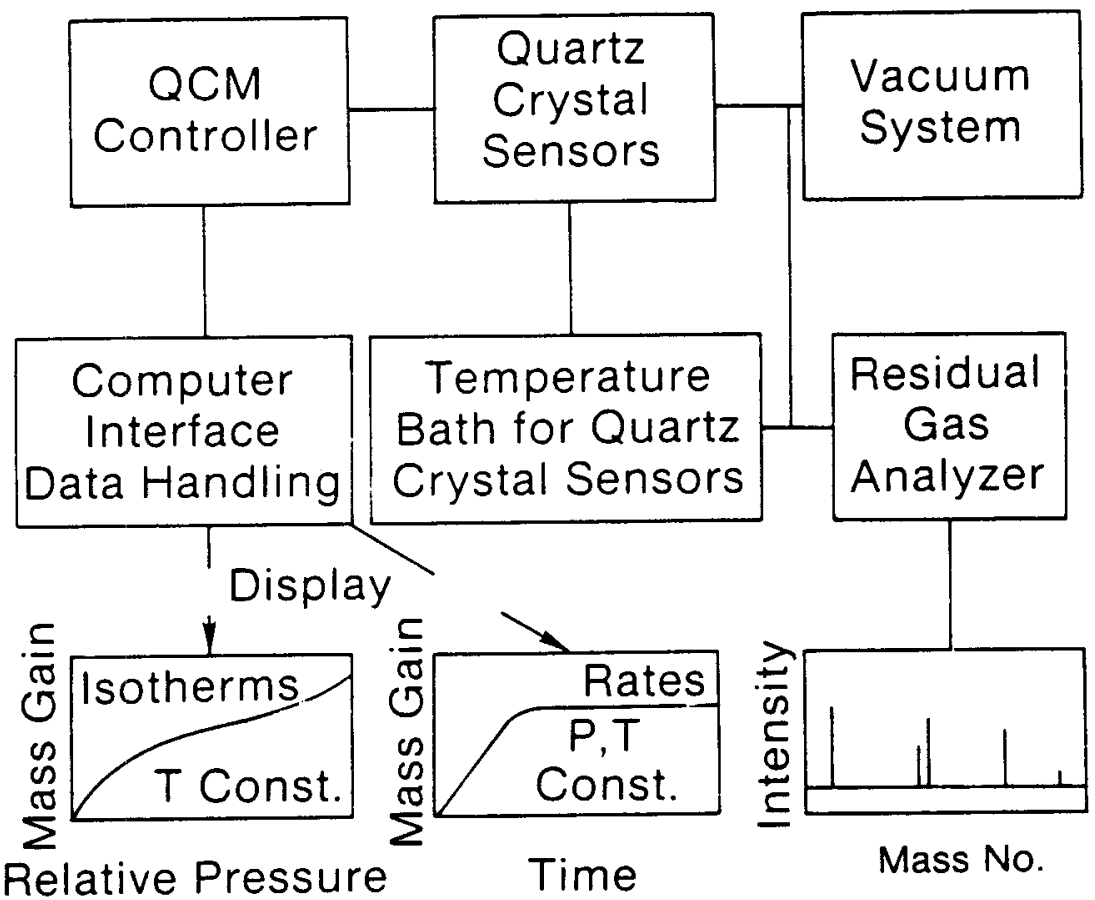

Figure 2-1. Block diagram showing the principal components of a QCM apparatus

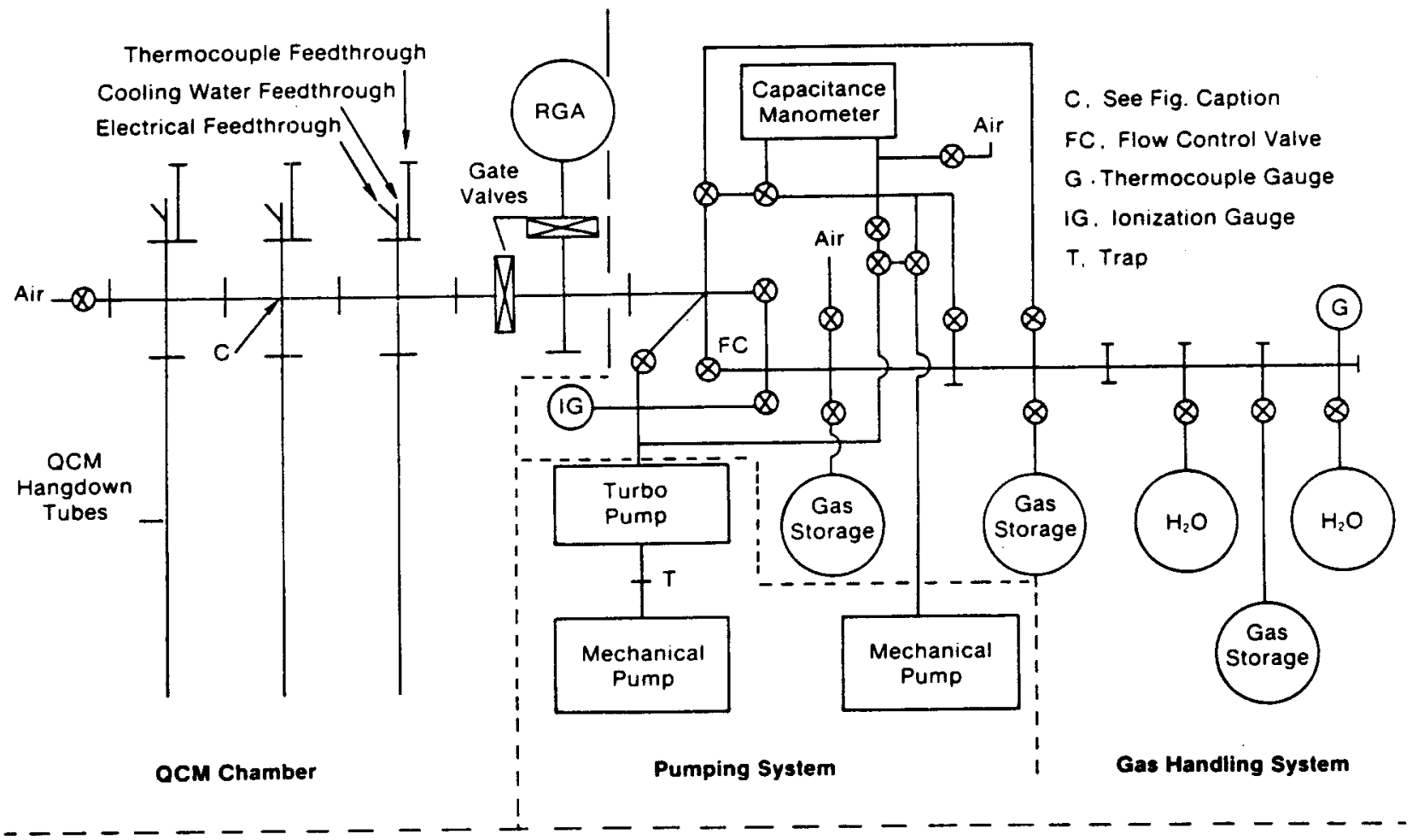

Figure 2-2. Schematic of vacuum system for QCM apparatus 
components of the vacuum system include a source of pure water vapor, capacitance manometer, valves for manipulating gas pressures, pumps, and lowpressure gauges. Sample temperatures are measured with thermocouples. Detailed descriptions of the QCM and vacuum chamber components are available (Czanderna and Thomas 1986).

\subsection{Procedures Used for Determining Isotherms}

After mounting the polymers of interest onto QCs and obtaining the mass of the attached polymer, the crystal was then attached to the oscillator head and bolted onto the vacuum system. The sample chamber was pumped to the $10^{-8}$ torr range with the sample at about $22^{\circ} \mathrm{C}$, and the oscillator mass was zeroed after the mass loss or gain was equilibrated. The system temperature was equilibrated to $22.1^{\circ} \mathrm{C}$, and water was admitted to the samples to a pressure of 1 torr. The system was allowed to equilibrate (both pressure and mass measurements). The water vapor pressure was then increased in about 2-torr increments, and the pressure and mass measurements were taken during the approach to equilibrium and after equilibrium was reached. After reaching the desired maximum pressure ( 16 torr in this work), the process was reversed by decreasing the water-vapor pressure in about 2-torr decrements followed by equilibration intervals. (There is no design restriction for making pressure changes of about 2 torr, which were chosen for our convenience; any desired pressure change can be chosen up to 20 torr at $22.1^{\circ} \mathrm{C}$. Higher pressures can be studied by increasing the ambient temperatures of the entire QCM and vacuum apparatus.)

For screening the polymers prepared in 1988, isotherms were determined at $22.1^{\circ} \mathrm{C}$ in pure water vapor using the QCM. The polymer-coated QC was mounted on the QC holder and evacuated to $<10^{-7}$ torr, which was usually $2 \times 10^{-8}$ torr, until constant mass readings were observed. The mass lost during evacuation has been used to correct the sample mass measured prior to evacuation.

In general, data for the first isotherm determination were obtained at about $5 \%, 10 \%, 20 \%, 30 \%, 40 \%, 50 \%, 60 \%, 70 \%$, and $80 \%$ R.H. by increasing the water vapor pressure from a vacuum of less than $10^{-7}$ torr to an initial pressure of about 1 torr ( $5 \%$ R.H.) and monitoring the uptake for about $45 \mathrm{~min}$. The capacity changes reported in the isotherms for all polymers are relative to the sample mass after evacuation at $22.1^{\circ} \mathrm{C}$. The percentage of water uptake was calculated by multiplying the area of polymer times the mass of water gained (or lost) times $100 \%$ and dividing by the mass of the polymer on the crystal. The percent water vapor uptake is given by

$$
\mathrm{H}_{2} \mathrm{O}=\frac{0.0785 \mathrm{~d}^{2}(\Delta \mathrm{m})}{\mathrm{M}}
$$

where $d$ is the diameter of the polymer coating on the QC (in $\mathrm{cm}$ ), $\Delta \mathrm{m}$ is the change of the QCM readings between vacuum and at any water vapor pressure in ( $\mathrm{ng} / \mathrm{cm}^{2}$ ), and $M$ is the sample mass (in $\mu \mathrm{g}$ ). M was corrected for the loss during outgassing by using $M=M_{0}-\pi d^{2} \Delta m_{0} / 4$ where $M_{0}$ is the sample mass measured in air and $\Delta \mathrm{m}_{0}$ is the $\mathrm{ng} / \mathrm{cm}^{2}$ loss during outgassing. The factor $0.0785 \mathrm{~d}^{2}$ results from the polymer coating covering a larger area than the sensing area $\left(0.58 \mathrm{~cm}^{2}\right.$ ) of the QC that yields the mass reading (in $\mathrm{ng} / \mathrm{cm}^{2}$ ). This factor then corrects the polymer mass (M) to the fraction of $M$ that is coating the sensing area of the QC. The maximum value for $d$ is $1.4 \mathrm{~cm}$, the diameter of the crystals used in this work. The actual value for $d$, which was 
obtained by combined visual and optical inspection of the polymer coating, typically ranged between 1.2 and $1.3 \mathrm{~cm}$.

The percentage of R.H. was calculated by multiplying the Baratron pressure reading times $100 \%$ and dividing by the saturation pressure of water at the system temperature. These calculations were simplified by carrying out our sorption studies at $22.1^{\circ} \mathrm{C}$ where the saturation vapor pressure of water was taken as 20.0 torr. The actual vapor pressure at $22.1^{\circ} \mathrm{C}$ was 19.95 torr. Thus, each 1 torr corresponds to $5 \%$ in R.H., where R.H. is the most widely used representation of the partial pressure of water in desiccant cooling research, development, and applications.

Isotherm shapes obtained by the QCM compare favorably with those measured by other methods. Examples of isotherms obtained with the QCM are given in prior reports (e.g., Czanderna and Thomas 1987a) and in Section 4 of this report. The water uptake is accurate within the limits described above.

\subsection{Kinetic and Cyclic Stability Studies}

Procedures were developed prior to this report for using the QCM apparatus for studying the adsorption and desorption kinetics as well as the cyclic stability of the sorption performance. These procedures, which were only used qualitatively for the screening efforts in 1988, are described in Appendix $F$.

\subsection{Procedure for Mounting Polymers on QCs for Sorption Performance Measurements}

Standard procedures were developed in 1986 and 1987 for mounting polymers on QC for study in the QCM apparatus (Czanderna 1988, Section 4.2).

\subsection{Installation of a Sartorius Microbalance}

The need for placing an existing SM into operation was established in early 1987. During 1988, it was attached to the gas handling and pumping station of the present QCM apparatus (as shown in Figure 2-3). The SM retains all the essential advantages of the QCM cited in Appendix $E$ and also eliminates all the limitations cited. The principal limitation of the SM, or any other beam microbalance, is that only one sample can be studied at a time. The capacity of the balance is $5 \mathrm{~g}$ with a sensibility of less than $1 \mathrm{\mu g}$. Samples of any configuration can be suspended in an appropriate container (e.g., a hemispherical gold cup), and accuracy to better than $0.01 \%$ can be easily assured. As of December 1989, the SM system is ready to be tested for operability. 


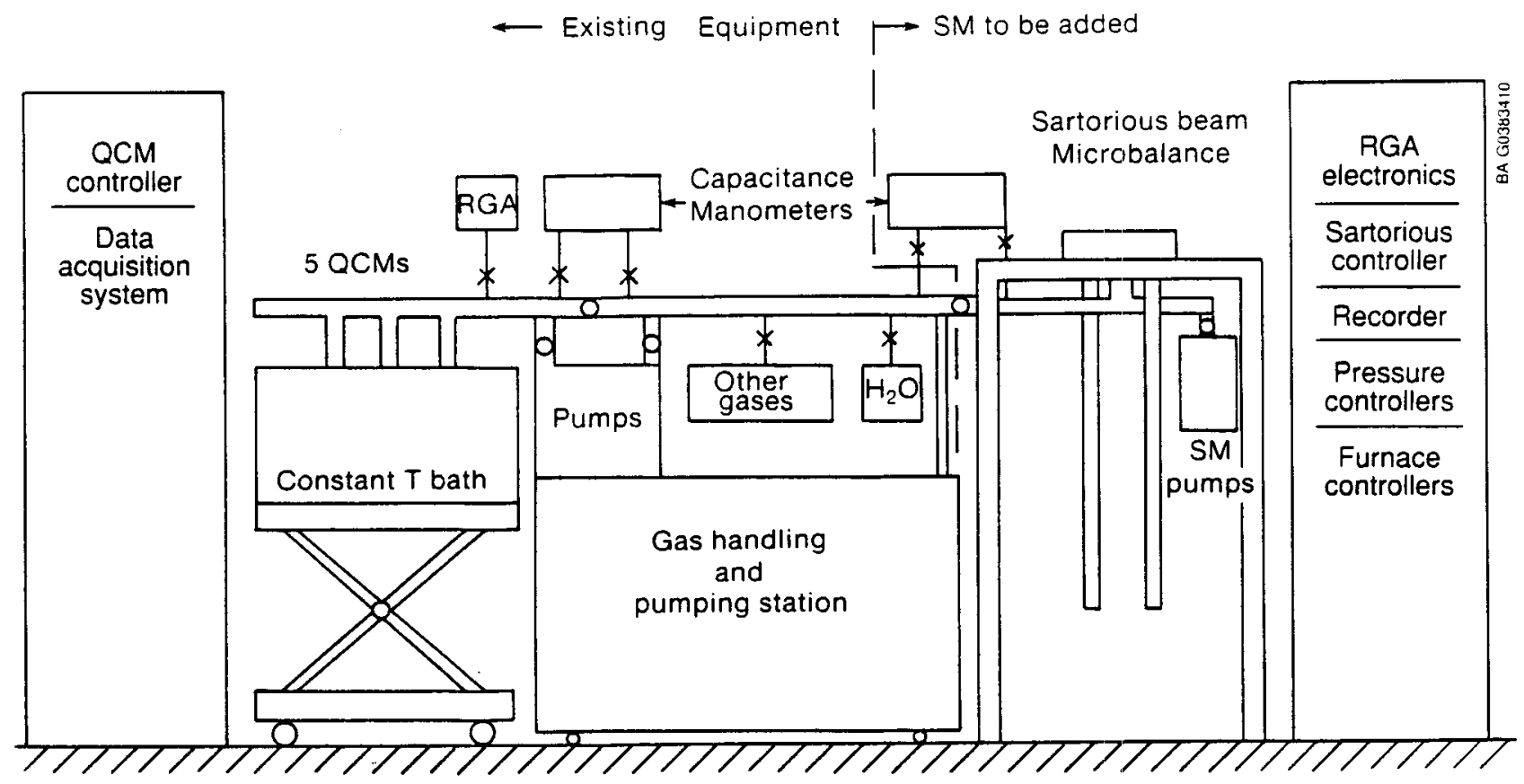

Figure 2-3. Block diagram illustrating arrangement of a combined QCM and SM apparatus 


\subsection{PREPARATION OF POLYMERS}

Polymers studied for sorption performance were obtained from commercial sources, from preparation procedures developed internally for modification studies, and from synthesis procedures for preparing a cross-linked hydrogel. The detailed preparation procedures are described in this section. We have chosen to focus our modification activities this year on PSSASS and SPSS. Both of these ionic polymers have the structure:

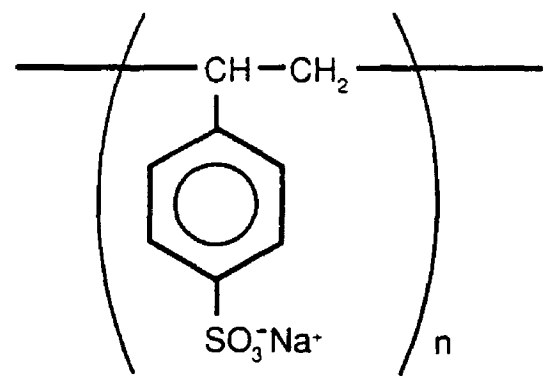

where $\mathrm{n}$ is the number of repeating units. SPSS samples are commercially available with a narrow MW distribution, for a wide range of MWs, and with $90 \%$ sulfonation. The percent sulfonation specifies the number of $\mathrm{SO}_{3}{ }^{-}$groups attached to the phenyl group (as shown) where $100 \%$ corresponds (ideally) to one $\mathrm{SO}_{3}{ }^{-}$per phenyl group. A polymer that is $20 \%$ sulfonated simply means one of every five phenyl groups has one $\mathrm{SO}_{3}{ }^{-} \mathrm{Na}^{+}$group attached. PSSASS samples are commercially available but the degree of sulfonation is usually not available from the supplier. Sulfonation for PSSASS can exceed $100 \%$ due to multiple sulfonation of phenyl groups (e.g., at the meta or ortho positions). The MW of the polymer depends on $n$, the percent sulfonation, and the counterion, if the acid form of PSSA is exchanged with a different counterion, i.e., $\mathrm{Li}^{+}$ for $\mathrm{H}^{+}$instead of $\mathrm{Na}^{+}$. In 1988, we studied PSSASS with various MWs and sulfonation percentages.

\subsection{Commercially Available Polymers}

Efforts were focused on studying PSSASS and SPSS of those candidates Iisted in Section 1.4. Because they are readily available, commercially available polymers were used to study the influence of $M W$ on isotherm shape. The sources of commercially available polymers used for sorption studies are given in Table 3-1. (The PAAAS and CSSS polymers were characterized to assist another SERI task.)

\subsection{Preparation of Partially Sulfonated Polgstyrenes}

\subsubsection{Materials}

The partial sulfonation reaction of polystyrene requires careful attention to several details, specified in Section 4.1 , to avoid secondary reactions, such as cross-linking. Basically, finely divided polystyrene* (PS) powder is dissolved at room temperature into dichloroethane (DCE) ( $1 \%$ to $2 \%$ ), to which the

*The polystyrene samples used were from Polysciences, Inc.: MW 6,000 (lot \#62716) and MW 50,000 (lot \#54689). 
Table 3-1. Commercially Available Polymers Characterized for Water-Vapor Sorption Performance

\begin{tabular}{|c|c|c|c|}
\hline Acronym & Source & Pol ymer & Comments \\
\hline CSsS & $\begin{array}{l}\text { Scientific Polymer } \\
\text { Prod., Inc. } \\
\text { Cat. \#023 }\end{array}$ & Cellulose sulfate sodium salt & Isotherms have neglible hysteresis \\
\hline PAAAS & $\begin{array}{l}\text { Polysciences, Inc. } \\
\text { Cat. \#3311 }\end{array}$ & Polyacrylic acid ammonium salt & $M W=250,000$ \\
\hline PSSASS & $\begin{array}{l}\text { Polysciences, Inc. } \\
\text { Cat. \#8773 } \\
\text { National Starch Co. } \\
\text { Versa TL } 77, \text { TL } 125 \text {, } \\
\text { and TL } 501\end{array}$ & $\begin{array}{l}\text { Polystyrene sulfonic acid } \\
\text { sodium salt }\end{array}$ & $\begin{array}{l}\text { MW } 500,000 \text { (powder). Available in } \\
\text { both water soluble form and cross- } \\
\text { linked beads. (The latter could } \\
\text { not be studied with the QCM.) The } \\
\text { Versa TLs are in liquid form. }\end{array}$ \\
\hline SPSS & $\begin{array}{l}\text { Scientific Polymer } \\
\text { Prod., Inc. } \\
\text { Cat. \#'s 618,619, } \\
621,622,623,625 \\
\text { and } 628\end{array}$ & sodium polystyrene sulfonate & $\begin{array}{rr}M W & 1,200,000(\# 628) \\
M W & 178,000(\# 625) \\
M W & 66,100(\# 623) \\
M W & 38,100(\# 622) \\
M W & 17,400(\# 621) \\
M W & 4,000(\# 619) \\
M W & 1,800(\text { (\#618) }\end{array}$ \\
\hline
\end{tabular}


proper amount of chlorosulfonic acid ( 0.2 to 0.8 mol-equivalent) is added under vigorous stirring. As sulfonation proceeds, the PS becomes insoluble, and the reaction is complete in 15 to $30 \mathrm{~min}$. Separation of the polyelectrolyte is then accomplished by water extraction, neutralization, dialysis, and solvent evaporation.

Characteristic details of the syntheses for sample MK1-88-3/4 are: $1.279 \mathrm{~g}$ PS $(M W=6,000)$ was dissolved in $102 \mathrm{ml}$ DCE in a $1-\ell$, three-neck, round-bottom reaction flask. Then, 0.6 mol-equivalent $(0.84 \mathrm{~g})$ chlorosulfonic acid in $100 \mathrm{ml}$ DCE was added dropwise with vigorous stirring at room temperature over a 3-h period. The reaction was allowed to proceed for another $30 \mathrm{~min}$, yielding a straw-colored solution and a precipitate on the side of the reaction flask. While stirring, we added $100 \mathrm{ml}$ of deionized water to extract the water-soluble reaction product. An excess of sodium carbonate $\left(0.63 \mathrm{~g} \mathrm{Na}_{2} \mathrm{CO}_{3}\right.$ in $100 \mathrm{ml} \mathrm{H}_{2} \mathrm{O}$ ) was added to neutralize the free acid. After standing overnight, the organic (MK1-88-4) and aqueous (MK1-88-3) layers were separated, filtered, and the solvents removed with a Rotovap.

A complete listing of all preparations of PSSASS is given in Table 3-2. Those in Series 1 were prepared by neutralizing the acid form of PSSA with an excess of sodium carbonate followed by dialysis purification against pure water. Those in Series 2 were prepared to the acid form of PSSA but were not neutralized. Those in Series 3 were prepared by neutralizing the acid form of PSSA with an equivalent concentration of sodium hydroxide.

\subsubsection{Purification}

The water-soluble sodium salts of the partially sulphonated polystyrenes from Series 1 were purified from excess sodium carbonate via extensive dialysis against deionized water using Spectra/Por 6 membranes (MW-cutoff 1000). The dialysis procedure took about 4 to 5 days and was monitored by conductance measurements. The dialyzed material was isolated on a Rotovap and dried to constant weight in a vacuum oven at $70^{\circ} \mathrm{C}$. The water-insoluble products (from the organic layer) were washed repeatedly with deionized water and vacuumdried to constant weight as mentioned above.

The water extracts from the acidic reaction products of Series 2 were carefully neutralized with $1 \mathrm{~N}$ NaOH by potentiometric titration to $\mathrm{pH} 7$ and used in the sorption experiments without further purification.

\subsubsection{Characterization}

The degree of sulfonation (or mol-fraction of sulfonate groups) was determined from elemental analysis performed by Huffmann Laboratories (in Golden, Colorado). A typical analysis for a PSSASS (MK2-88-27) is $50.7 \% \mathrm{C}, 4.8 \% \mathrm{H}$, $11.6 \% 0$, and $9.7 \% \mathrm{~S}$. The theoretical analysis for a $100 \%$ sulfonated PSSASS (one sulfonate per phenyl group) is $3.4 \% \mathrm{H}, 46.4 \% \mathrm{C}, 15.5 \% \mathrm{~s}, 23.2 \% \mathrm{0}$, and $11.1 \% \mathrm{Na}$.

Ultraviolet absorption spectra and extinction coefficients in aqueous solution were measured with a Perkin-Elmer Lambda 9 spectrometer. By taking the equivalent weight of the polyelectrolyte as $M=103 \alpha+104$, corresponding to $\left(\mathrm{C}_{8} \mathrm{H}_{7} \mathrm{SO}_{3} \mathrm{Na}\right)_{\alpha}\left(\mathrm{C}_{8} \mathrm{H}_{7}\right)_{1-\alpha}$, the equivalent extinction coefficients at the maximum $261 \mathrm{~nm}$ were calculated (see Table 4-1). 
Table 3-2. Listing of All Preparations of PSSASS

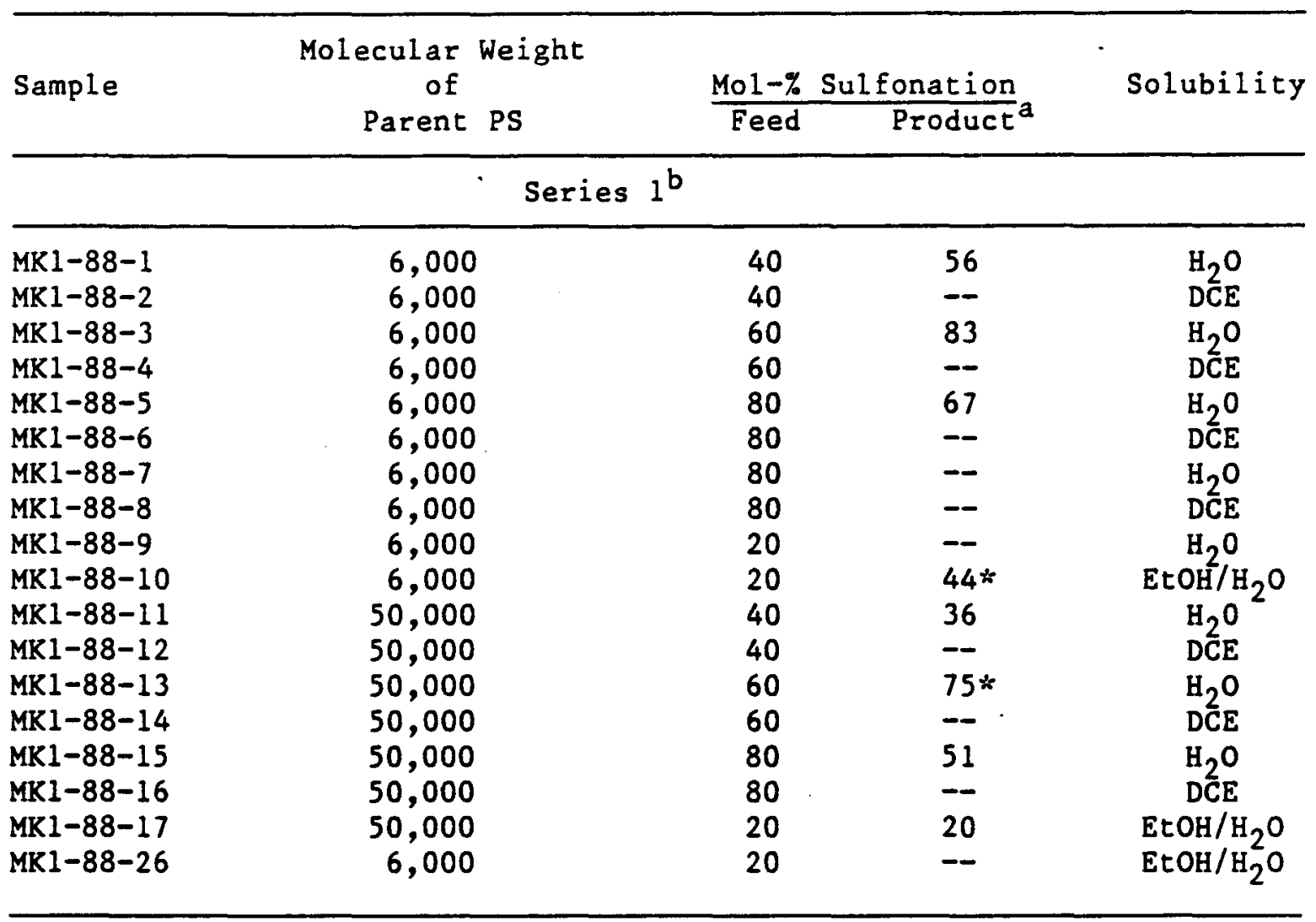

Series $2^{c}$

\begin{tabular}{lllll}
\hline MK2-88-27 & 6,000 & 60 & 58 & $\mathrm{H}_{2} \mathrm{O}$ \\
MK2-88-28 & 6,000 & 60 & -- & DCE \\
MK2-88-29 & 6,000 & 80 & 84 & $\mathrm{H}_{2} \mathrm{O}$ \\
MK2-88-30 & 6,000 & 80 & -- & $\mathrm{DCE}$ \\
MK2-88-31 & 6,000 & 40 & 48 & $\mathrm{H}_{2} \mathrm{O}$ \\
MK2-88-33 & 6,000 & 40 & -- & $\mathrm{DCE}$ \\
\hline \multicolumn{7}{c}{ Series 3 } & & \\
\hline RG19-52-2 & 6,000 & 40 & -- & $\mathrm{H}_{2} \mathrm{O}$ \\
RG19-52-3 & 6,000 & 80 & -- & $\mathrm{H}_{2}^{\mathrm{O}}$ \\
RG19-52-4 & 6,000 & 60 & -- & $\mathrm{H}_{2} \mathrm{O}$ \\
\hline
\end{tabular}

a Determined by elemental analysis; marked $(*)$ samples were not completely homogeneous.

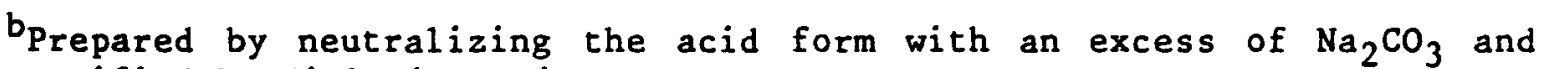
purified by dialysis against pure water.

CAcid form (not neutralized).

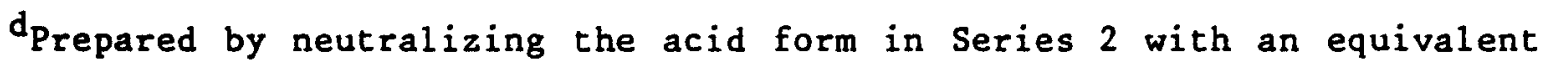
concentration of $\mathrm{NaOH}$. 


\subsection{Preparation of Acrylic Hydrogels}

\subsubsection{Sample Preparation}

The gels were prepared from $100 \mathrm{ml}$ of a mixture which contained $8 \mathrm{~m} \ell$ ( $7.38 \mathrm{~g})$ of the monomer $\mathrm{N}, \mathrm{N}$-diethylacrylamide (DEAAm), $0.2 \mathrm{~g}$ of the cross-1inking agent $\mathrm{N}, \mathrm{N}$-methylene bisacrylamide (BIS), $20 \mathrm{mg}$ of the initiator ammonium persulphate, and $20 \mathrm{mg}$ of the accelerator sodium pyrosulphite (anhydrous). To prepare ionized networks, sodium methacrylate (MNa) was added to the mixture in such amounts that the molar fraction of MNa related to the total amount of monomers was $\mathrm{X}_{\mathrm{MNa}}=0.03,0.05,0.07$, and 0.09 . All components with the exception of sodium pyrosulphite were dissolved in deionized water and flushed with argon. After that, the mixture was cooled to $10^{\circ} \mathrm{C}$, pyrosulphite was added, and then the solution was stirred and dosed into 1-cm-diameter test tubes. The test tubes were again flushed with argon and sealed. The polymerization proceeded at $3^{\circ} \mathrm{C}$ for $18 \mathrm{~h}$. The samples were allowed to warm to room temperature for $6 \mathrm{~h}$. After removing the gels by breaking the glass tubes, the rods were washed with water before being cut into $\sim 1 \mathrm{~cm}$ length cylinders; the rod ends were discarded. The cylinders were then stored for $24 \mathrm{~h}$ in an aqueous $0.005 \mathrm{M}$ sodium nitrite solution which was later washed out in deionized water. A listing of all preparations of acrylic hydrogels is given in Table 3-3.

Table 3-3. All Preparations of Acrylic Hydrogels

\begin{tabular}{lc}
\hline Sample & $\begin{array}{c}\text { Molar Ratio } \\
\left(\mathrm{X}_{\mathrm{MNa}}\right)\end{array}$ \\
\hline PG1-109-3 & 0.03 \\
PG1-109-5 & 0.05 \\
PG1-109-7 & 0.07 \\
PG1-109-9 & 0.09 \\
\hline
\end{tabular}

\subsubsection{Swelling Characteristics}

The cylindrical specimens were placed in glass bottles filled with deionized water, and the sealed bottles were immersed in thermostats set at $30^{\circ}, 40^{\circ}$, $50^{\circ}, 60^{\circ}$, and $70^{\circ} \mathrm{C}$. After the cylinders had swelled for one week, the $\mathrm{pH}$ of the water in the glass bottles was adjusted to 7.5 to 8.0 with $\mathrm{NaOH}$ (to guarantee that ionization equaled the molar fraction of $\mathrm{MNa}$ ). After another three days of swelling, the diameters of the cylinders were carefully measured using a digital micrometer. The temperature of all thermostats was then decreased by $5^{\circ} \mathrm{C}$ and the swelling was continued for another three days before the diameters were measured again. An average of five measurements were performed for each diameter. 


\subsection{EXPERIMENTAL RESULTS AND DISCUSSION OF SORPTION MEASUREMENTS ON DIFFERENT POLYMERS}

\subsection{Results of Synthesis and Modification Efforts}

\subsubsection{Partially Sulfonated Polystyrenes}

Partial sulfonation of polystyrene (PS) was carried out using chlorosulfonic acid in DCE (Mita, Okubo, and Ise 1976; Roth 1957). The most important problem to control was that of cross-linking - presumably due to sulfone formation resulting from attack of sulfonated groups on unreacted phenyl rings. The best results have been obtained by using finely divided PS of low MW $(6,000$ and 50,000$)$, low concentrations of reactants ( $1 \%$ to $2 \%$ ) pure solvents, efficient agitation, slow addition of the sulfonating agent, and low temperatures. Target percentages included $20 \%, 40 \%, 60 \%$, and $80 \%$ sulfonation. Although PS was soluble in DCE, the sulfonated products were not and precipitated out. In a first series of experiments (Series 1), the reaction mixture was neutralized with an aqueous solution of $\mathrm{Na}_{2} \mathrm{CO}_{3}$ which also doubled as an extraction medium for the hydrophilic sulfonated reaction products (unreacted PS and/or PS with low sulfonation remained in the organic DCE phase). After isolation of the reaction products from their solutions, the water-soluble products were purified from excess $\mathrm{Na}_{2} \mathrm{CO}_{3}$ by exhaustive dialysis, and the water-insoluble products from the organic phase were washed with water. A considerable material loss was noticed using the dialysis procedure for the purification of the sulfonated products. In view of this loss, we chose an alternative route to prepare the $\mathrm{Na}$ salt of PSSA by using a titration method to neutralize partially sulfonated PS (Series 2). All the PSSASS samples prepared within Series 1,2 , and 3 are listed in Table 3-2. It was further noticed that the water-soluble fraction of the reaction products decreased with decreasing target percent sulfonation. For example, $20 \%$ sulfonated PS was found to be insoluble in DCE and water, but soluble in ethanol/water mixtures $\left(e . g ., \mathrm{EtOH} / \mathrm{H}_{2} \mathrm{O} \approx 4: 1\right)$.

The extent of sulfonation for selected samples (see Table 3-2) was determined by elemental analysis. The percent sulfonation achieved ranged from $20 \%$ to $83 \%$, compared to targeted range of $20 \%$ to $80 \%$. Individual results varied by up to $30 \%$ from the targeted range, so elemental analysis was crucial for obtaining the correct percent sulfonation. Alternatively, the content of sulfonic acid groups in PSSA may be determined by titration with base. However, the water extracts of the reaction products of Series 2, with which we attempted this analysis method, contained residual $\mathrm{HCl}$ (another reaction product), and thus gave incorrect values.

Another aspect of analysis is the determination of the polymer content of a solid sample (which may also contain water) or of a solution. Two methods have been used in our work: an evaporation/gravimetry method and a spectrophotometric method. The former is carried out by evaporation of water at $130^{\circ} \mathrm{C}$ from PSSASS solutions and drying to constant weight at $70^{\circ} \mathrm{C}$. Evaporation is not a practicable method for the isolation of the polyacid PSSA, since it decomposes at about $110^{\circ} \mathrm{C}$ (Butler, Robins, and Shooter 1957). It should be noted that freeze-dried samples of PSSASS still contain about $2 \%$ water (Szymczak, Holyk, and Ander 1975). 
The latter method uses ultraviolet absorption at the maximum of $\sim 261 \mathrm{~nm}$ to determine the polymer content from Lambert-Beer's law. The extinction coefficients calculated for selected partially sulfonated PSSASS samples in water are 1 isted in Table 4-1 and compared to literature values in Figure 4-1. We noticed that the value of the extinction coefficient depends strongly on the degree of sulfonation. Equivalent extinction data for various unpurified, commercial PSSASS samples were found to lie considerably below the literature value for atactic PSSASS of 389 (Carroll and Eisenberg 1966) (e.g., 244 to 277). This may indicate the presence of low MW salt impurities (e.g., $\mathrm{Na}_{2} \mathrm{SO}_{4}$ ) in these commercial samples since variations in the ionic environment of the polymer have been found to affect the extinction coefficient (Carroll and Eisenberg 1966). This salt effect is ascribed to the transition moments of the aromatic rings being reduced when they are brought into proximity as a result of the electrostatic repulsions between them being decreased by the shielding effect of the low MW salt (Aylward 1975). These variations in the interactions of the phenyl groups may play a role in stabilizing particular coil conformations which may be of consequence for the sorption performance of PSSASS in a desiccant application.

Table 4-1. Specific and Equivalent Extinctions of the Sodium Salt of Partially Sulfonated Polystyrene (in Water at $25^{\circ} \mathrm{C}$ )

\begin{tabular}{lccc}
\hline Sample & $\begin{array}{c}\text { Degree of } \\
\text { Sulfonation }\end{array}$ & $\begin{array}{c}\text { Specific Extinction } \\
\text { Coefficient }\left(\varepsilon_{\text {sp }}\right)\end{array}$ & $\begin{array}{c}\text { Equivalent Extinction } \\
\text { Coefficient }\left(\varepsilon_{\text {eq }}\right)\end{array}$ \\
\hline MR1-88-1 & 0.56 & 1.66 & 269 \\
MK1-88-3 & 0.83 & 1.89 & 358 \\
MK1-88-5 & 0.67 & 1.86 & 321 \\
MK1-88-11 & 0.36 & 1.35 & 191 \\
MK1-88-13 & 0.75 & 1.55 & 281 \\
\hline
\end{tabular}

Further evidence that interactions of the phenyl groups vary as a function of degree of sulfonation is given in Figure 4-1, where it is seen that the extinction coefficient varies its linear dependency on the degree of sulfonation $\alpha$ around $65 \%$ sulfonation, a composition below which an increased isolation of sulfonated phenyl groups can be expected. The increase in the value of the extinction coefficient for samples with $\alpha>1$ is probably due to disulfonation of some of the phenyl rings.

\subsubsection{Acrylic Hydrogels}

Gel samples were prepared by the copolymerization of $\mathrm{N}, \mathrm{N}$-diethylacrylamide with $\mathrm{N}, \mathrm{N}$-methylenebisacrylamide in the presence of 92 vol-\% water. To prepare ionized networks, various amounts of sodium methacrylate (MNa) ( 3 to 9 mo1-\%) were added to the copolymerization mixture.

Swelling measurements were performed under equilibrium conditions in water as a function of temperature for all synthesized gels. The swelling ratio $X$ of all gels related to the state of network formation was determined by using the relation

$$
X=(D * / D)^{3}=V * / V,
$$




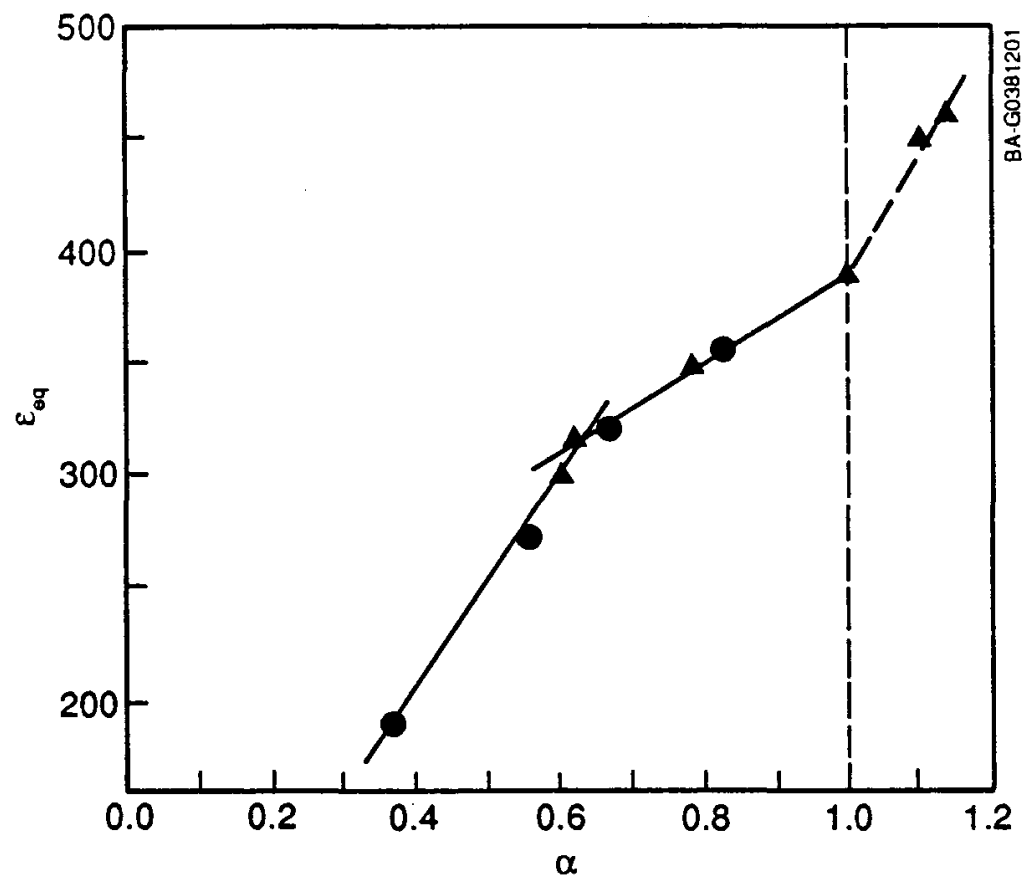

Figure 4-1. Equivalent extinction coefficients ( $\varepsilon$ eq.) of the sodium salt of partially sulfonated polystyrene in water at $25^{\circ} \mathrm{C}$ as a function of the degree of sulfonation (a)

where $D$ and $D *$ are diameters of the sample after swelling and after being prepared, respectively; and $V$ and $V *$ are gel volumes after swelling and after being prepared, respectively. The last equality in Eq. 4-1 implies isotropic swelling.

Each point on the temperature dependence of $X$ given in Figure 4-2 represents an average from five measurements. The results shown in Figure 4-2 indicate a change in the curve in the range $\mathrm{T} \approx 53^{\circ} \mathrm{C}$, corresponding to a phase transition, for gels with $\mathrm{X}_{\mathrm{MNa}}=0.03$. The different temperature dependence of curves $I$ and $I I$ is due to different cross-linking conditions for these two samples. The transition temperature rises with increasing ionic content of the gels and seems to lie above the boiling point of water for the gels with $\mathrm{X}_{\mathrm{MNa}}=0.05,0.07$, and 0.09 . The observed volume collapse is reversible and corresponds to a 16-fold decrease in the volume of the gel with $X_{M N a}=0.03$.

Figure 4-3 compares a swollen gel to a dry gel at room temperature. The potential sorption capacity of this gel is in excess of $10,000 \%$ of its dry weight.

We also attempted to coat a QC with the aqueous pre-gellation mixture for kinetic and isotherm measurements in the QCM, but we were not successful in producing a uniform coat on the crystal. It appears that other solvent systems (which may affect the gel structure) need to be used to obtain uniform coatings. Furthermore, the QCM may not be the proper mass-measuring system to be used in our case due to the high damping characteristics expected for our highly swollen gels. It is well known in the QCM literature that special procedures are required when measuring liquid-like materials (Lu and Czanderna 1984). 


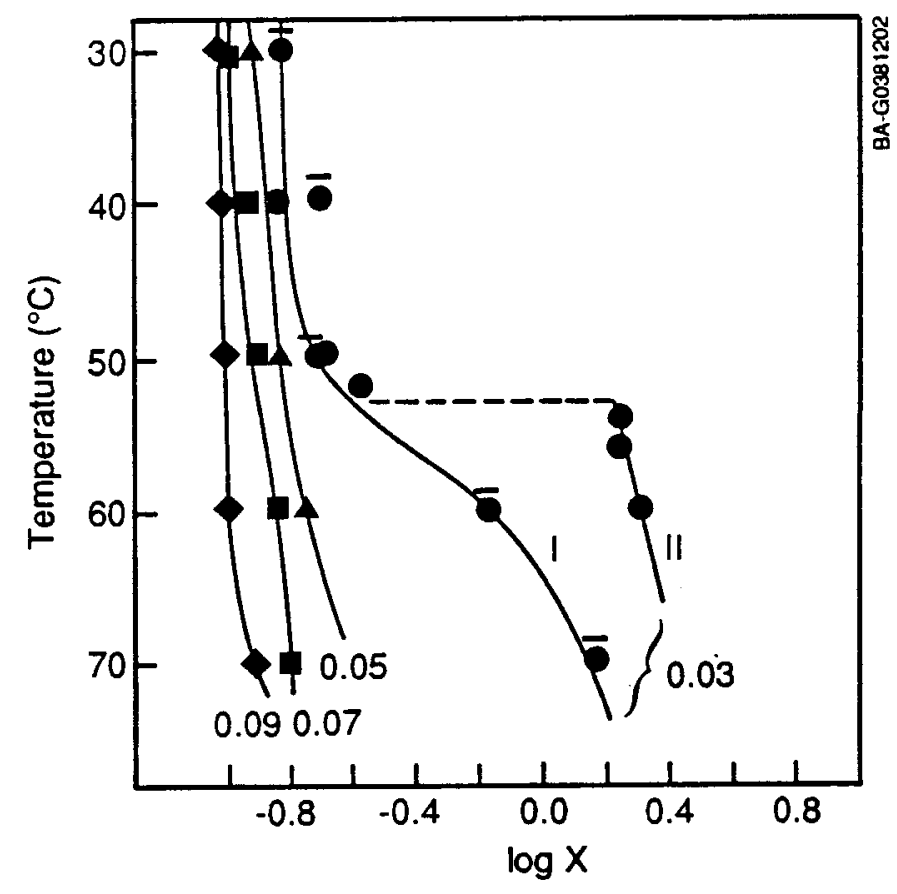

Figure 4-2. Temperature dependence of the swelling ratio $X$ for acrylic hydrogels

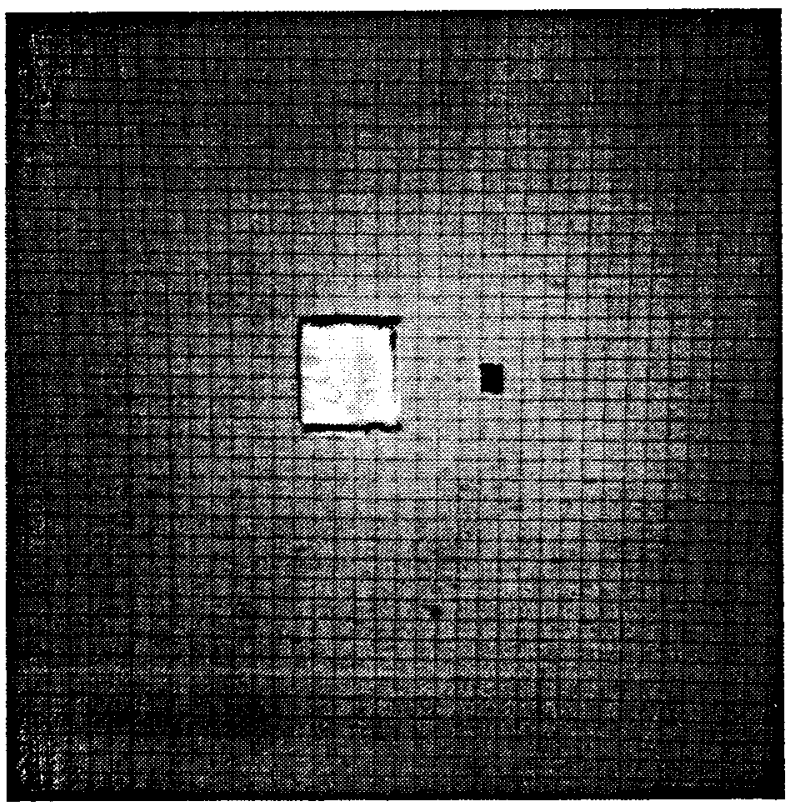

Figure 4-3. Comparison of a swollen gel (left) to a dry gel (right) 
Another factor of concern is the mechanical stability of the rather fragile gels. The volume collapse caused considerable cracking of the cylindrical gel samples used in our preliminary tests. Modification of cross-linking densities may help here, although probably with a sacrifice in sorption capabilities. Further tests need to include, besides additional structural modification studies, sorption/desorption experiments at variable relative humidity values, as well as cycling effect studies. It is likely that a hydrogel of this type would need to be grafted unto a structural support, e.g., a structural polymer. We have made no attempt to assess the engineering challenge offered by swelling polymers.

\subsection{Isotherms of Polymers Studied}

of the criteria for a candidate ADM, the determination of an adsorption isotherm provides four important pieces of data: (1) the shape, (2) the capacity and possible capacity change between $5 \%$ and $60 \%$ R.H., (3) the absence or presence of hysteresis between the adsorption and desorption legs of the isotherm, and (4) the kinetics of the sorption or desorption process after each pressure change. Data for (1), (2), and (3) are presented and discussed in this section, but data for (4) can only be discussed qualitatively because of the limitations imposed by the MacSym 2 - printer mode of data acquisition, plus its failure in June 1988. In almost all cases, there was no hysteresis so the data in the figures represent both adsorption and desorption without making a distinction for the various data points. The one exception is discussed.

\subsection{Isotherms Measured on Commercially Available Polymers of Different MW}

The isotherms determined with the QCM apparatus on purchased Versa TLs and SPSS are shown in Figures 4-4 and 4-5. The sample mass given on each figure is the mass measured in air and corrected for losses on outgassing. The polymers used to obtain these isotherms are those listed in Table 3-1.

From the sorption measurements of PSSASS and SPSS with different MW, we found that the isotherm shape depends on the MW. For PSSASS, the isotherm shape (not capacity) seems to be better at a MW of 70,000 than at 125,000 or 500,000. The latter tends towards a slightly more linear behavior than the lower MW materials. A lower capacity per unit mass was obtained for Versa TL 125, i.e., curves for 0.230 and $1.250 \mathrm{mg}$ samples. This result is anomalous for most samples studied. No attempt was made to deduce the cause of the disparity because the MW of these samples was outside those of greatest interest. However, it is possible that different percentages of sulfonation are present in the two samples. As mentioned earlier, the manufacturer does not provide the sulfonation percentages, and it was not deemed worthwhile to devote additional effort to determine the reason. For example, samples of different sizes of SPSS ( $M W=66,100$, Figure 4-5) produced comparable results. For SPSS, the best isotherm shapes seem to be obtained for MW between 5,000 and 66,100, but the optimum MW has not been deduced. Outside this MW region, the isotherms become more linear below $60 \% \mathrm{R} . \mathrm{H}$. There is also a decreased capacity of uptake at the highest MW. Pertinent data from the isotherms are summarized in Table 4-2. 


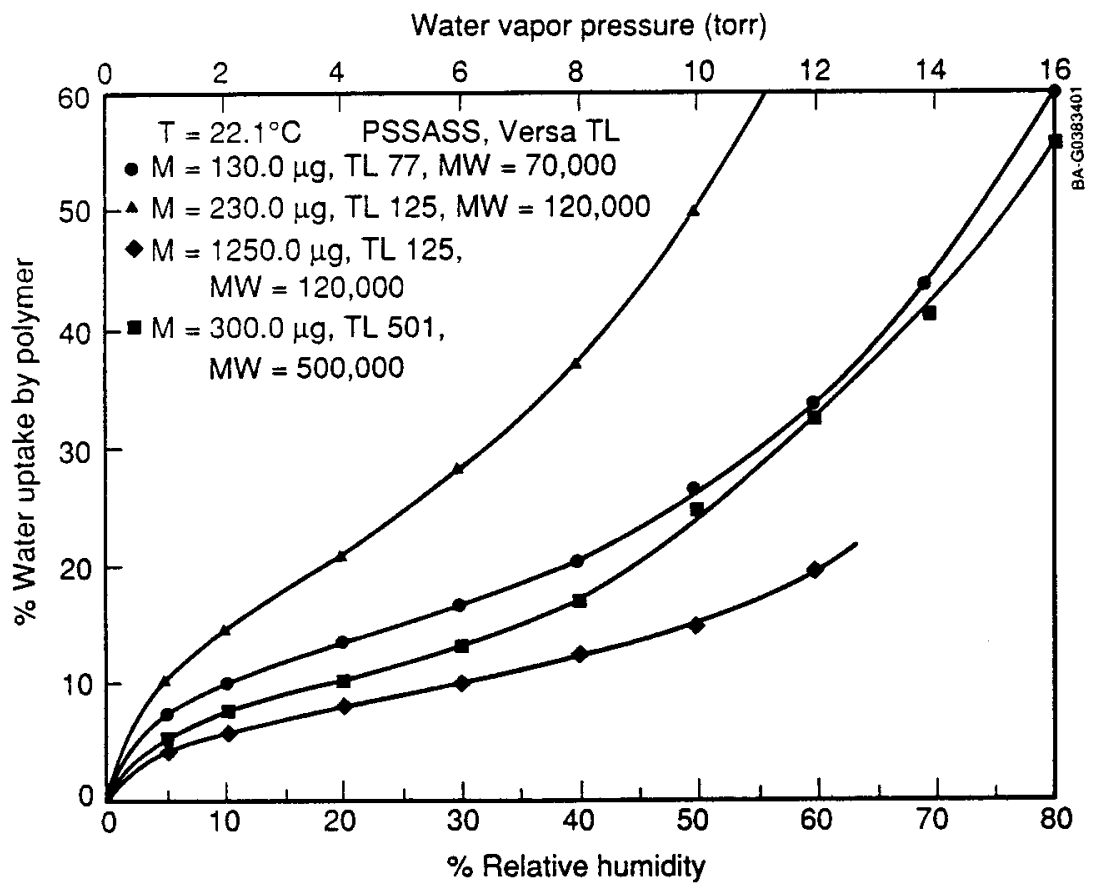

Figure 4-4. Water vapor adsorption isotherms at $22.1^{\circ} \mathrm{C}$ for National Starch Versa TL 77, TL 125, and TL 501

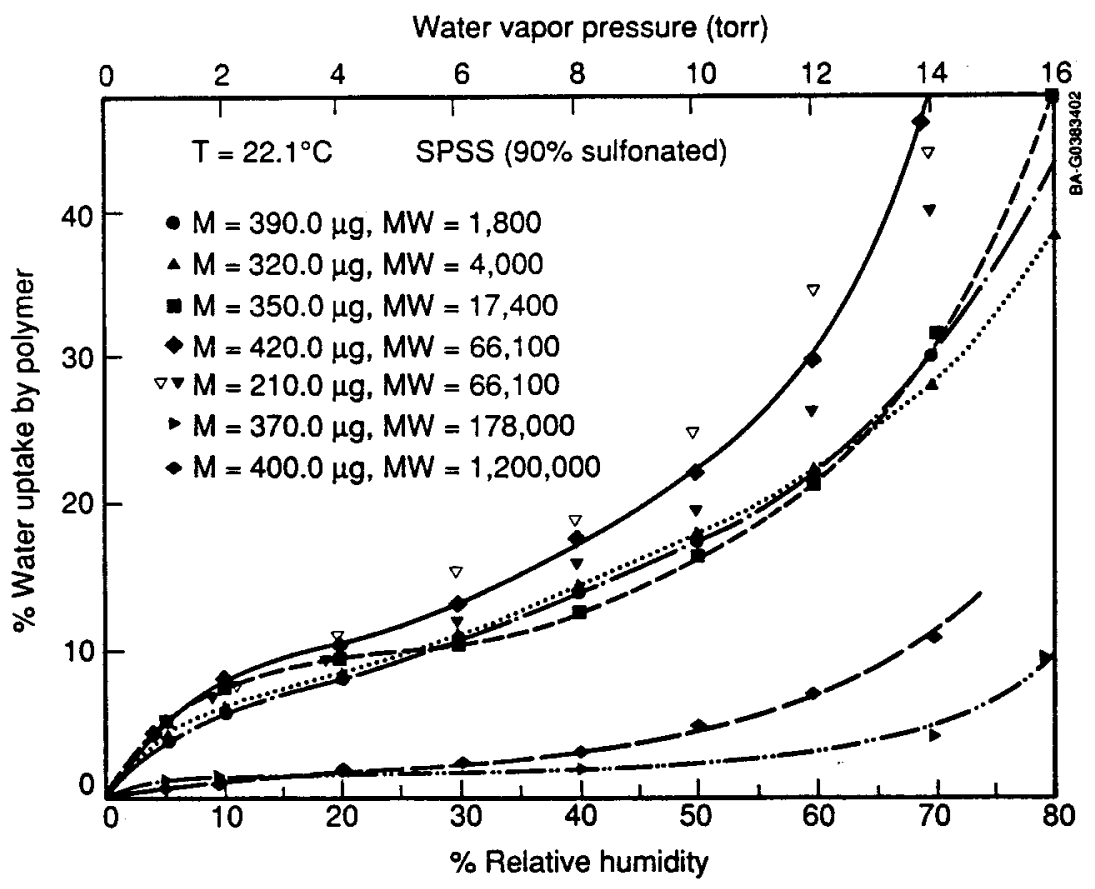

Figure 4-5. Water vapor adsorption isotherms at $22.1^{\circ} \mathrm{C}$ for different MW of SPSS. (The open triangles for MW of 66,100 and $210 \mathrm{\mu g}$ of SPSS are for desorption and the solid triangles are for adsorption.) 
Table 4-2. Summary of Isotherm Data for Polymers Studied as Potential ADM

\begin{tabular}{|c|c|c|c|c|c|c|c|c|}
\hline Acronym & $\begin{array}{l}\text { Fig. } \\
\text { No. }\end{array}$ & $\begin{array}{l}\text { Mass. } \\
(\mu g)\end{array}$ & $\begin{array}{l}\text { Is otherm } \\
\text { Type }\end{array}$ & $\begin{array}{l}\% \\
\text { Capacity } \\
\text { at } \\
80 \% \text { R.H. }\end{array}$ & $\begin{array}{l}\text { Capacity } \\
\text { Change } \\
\text { from } \\
5 \% \text { to } 60 \%\end{array}$ & Hysteresis & Kinetics & Other Comments \\
\hline PSSASS & $4-4$ & $\mathrm{VAR} *$ & 2 & VAR* & VAR* & Above $50 \%$ R.H. & Fast & $\begin{array}{l}\text { Excellent repeatability on } \\
\text { numerous multicycle runs. }\end{array}$ \\
\hline SPSS & $4-5$ & VAR* & 2 & VAR * & $\mathrm{VAR} *$ & Yes & East & $\begin{array}{l}\text { Hysteresis disappeared on } \\
\text { run } 4 \text {; capacity dropped } \\
\text { from } 60 \% \text { to } 30 \% \text {. }\end{array}$ \\
\hline PAAAS & $6-1$ & 395 & 2 & 16 & 7 & Yes & Fast & $\begin{array}{l}\text { Hysteresis becomes less } \\
\text { pronounced with cycling; } \\
\text { capacity decreases by a } \\
\text { factor of } 2 \text { through } 4 \\
\text { cycles. }\end{array}$ \\
\hline csss & $6-1$ & 286 & 2 & 16 & 6 & No & Fast & $\begin{array}{l}\text { Negligible hysteresis and } \\
\text { capacity change through } 4 \\
\text { cycles. }\end{array}$ \\
\hline
\end{tabular}

*VAR means variable, because multiple samples were run. 
Based on the data in Figures $4-4$ and $4-5$, the first modification of PSSASS has been to use PS with a MW of 6,000 and 50,000, which are available commercially. The second modification was to vary the percentage of sulfonation of the PS prior to forming the sodium salt. These isotherms are presented and discussed in Section 4.4 .

\subsection{Isotherms for PSSASS with Different Percent Sulfonation}

The second modification of PSSASS was to sulfonate the PS to the acid form (i.e., PSSA), and exchange the acid form with sodium ions to form PSSASS. The PSSAs were prepared with targeted sulfonic acid percentages of $20 \%, 40 \%, 60 \%$, and $80 \%$, which were then exchanged to form the corresponding PSSASS. The sorption data on these PSSASS samples indicate the capacity improves for the isotherms as the sulfonation percentage increases (as shown in Figures 4-6 and 4-7). No data are presented for $20 \%$ sulfonation because only partial isotherms were obtained and the capacity was lower for $40 \%$ sulfonation. The partial isotherms indicated the capacity at $60 \% \mathrm{R} . \mathrm{H}$. would have been below $8 \%$. More importantly, the data in Figure 4-6 show a monotonic increase in capacity from $40 \%$ to $80 \%$ sulfonation. The water uptake of sample $52-3$ in Figure $4-6$ is about twice that for SPSS (MW 4,000, Figure 4-5) and the isotherm shape is comparable. The samples in Figure 4-6 were prepared by using $\mathrm{NaOH}$ to titrate the PSSA to a preselected $\mathrm{pH}$. The isotherm shapes are BET Type 2, which is an improvement but not the final result desired.

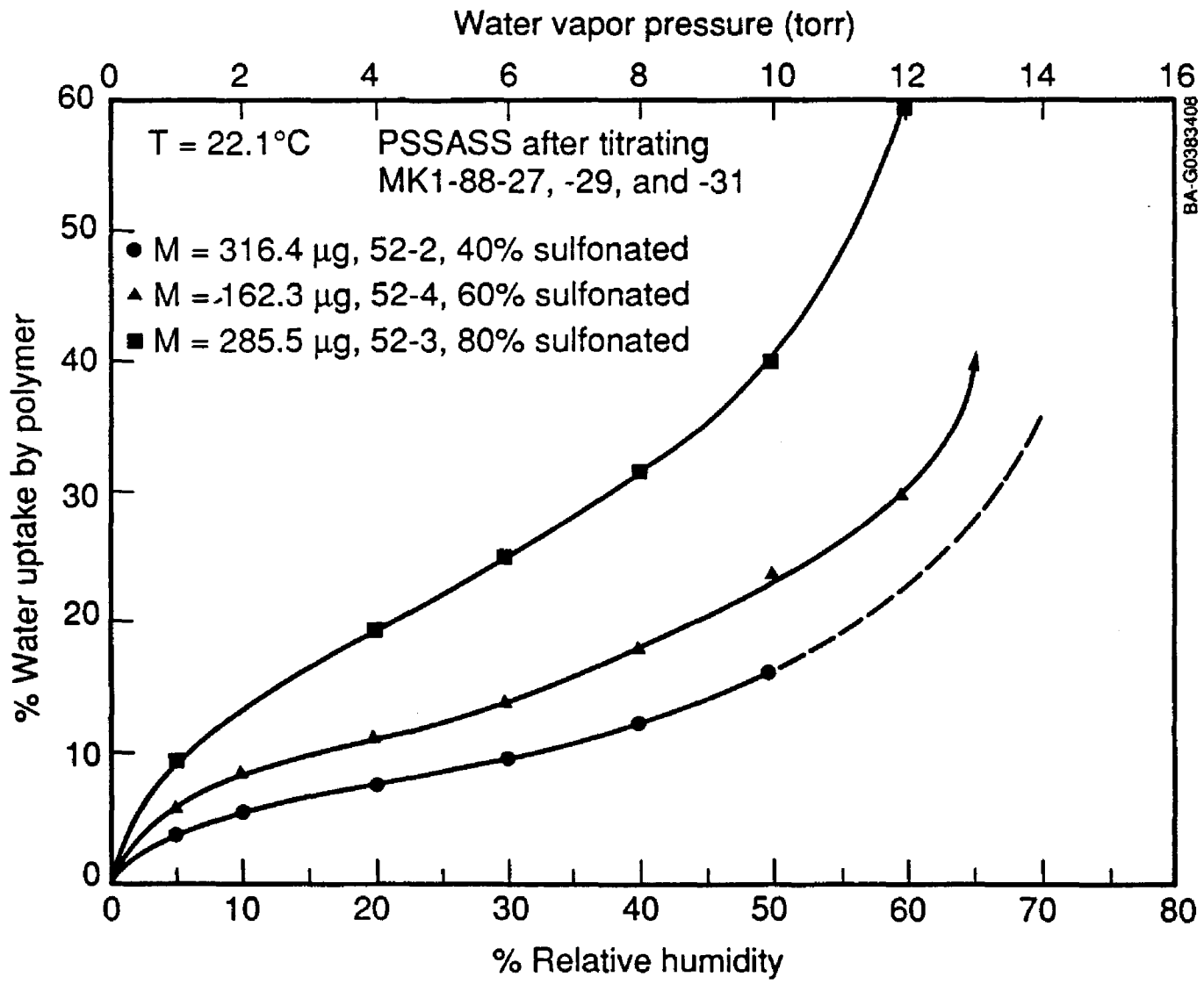

Figure 4-6. Water vapor adsorption isotherms at $22.1^{\circ} \mathrm{C}$ for SERI-prepared PSSASS (MW 6,000) for different targeted percent sulfonation 


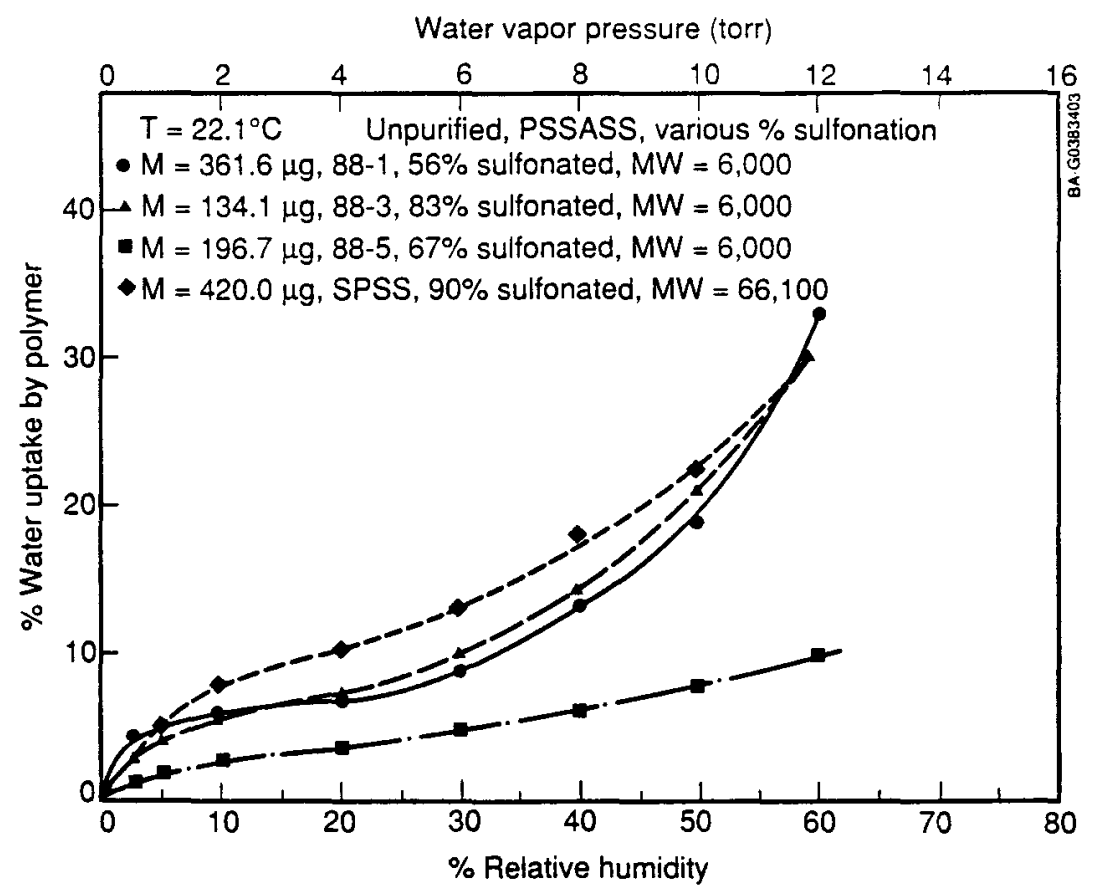

Figure 4-7. Water vapor adsorption isotherms at $22.1^{\circ} \mathrm{C}$ for SERI-prepared PSSASS (MW 6,000; unpurified) with different percent sulfonation compared with SPSS $(907, M W=66,100)$

The isotherms in Figure 4-7 are for unpurified PSSASS formed by neutralizing PSSA with $\mathrm{Na}_{2} \mathrm{CO}_{3}$ as described in Section 3.2.1. The capacities at $60 \% \mathrm{R} . \mathrm{H}$. are comparable to that of SPSS except for the $67 \%$ sulfonated, which is probably an anomaly for reasons given in section 4.5. The knee of the BET Type 2 isotherms seems to be sharper for the $56 \%$ sulfonated material. Further work is clearly needed to establish the sulfonation percentage that will produce an optimum combination of shape and capacity.

\subsection{Other Influences on PSSASS Isotherms}

Other influences alter isotherm shape and capacity. These include the influence of dialysis purification of the solvent in which PSSASS is dissolved, and the neutralization method as already shown in Section 4.4. It is important to note the \% water uptake on the ordinate of the figures in this section.

\subsubsection{Influence of Dialysis Purification}

Isotherms for SERI-prepared, partially sulfonated PSSASS are shown in Figures 4-8 and 4-9. These both show that dialysis purification (Section 3.2.2) dramatically reduced the capacity (by a factor of about 3 to 4 ) for PSSASS that remained in the aqueous phase. Furthermore, the isotherms in Figure 4-8 became less BET Type 2 and became borderline BET Type 3, thus, both the isotherm shape and capacity were changed in an undesirable direction. Although purified samples of PSSASS prepared with a higher MW PS $(50,000)$ yielded better capacity and BET Type 2 isotherm shapes (Figure 4-9), the capacity change between $5 \%$ and $60 \%$ R.H. is, at best, at the low borderline for an ADM. Accordingly, the dialysis purification procedure was abandoned at this 


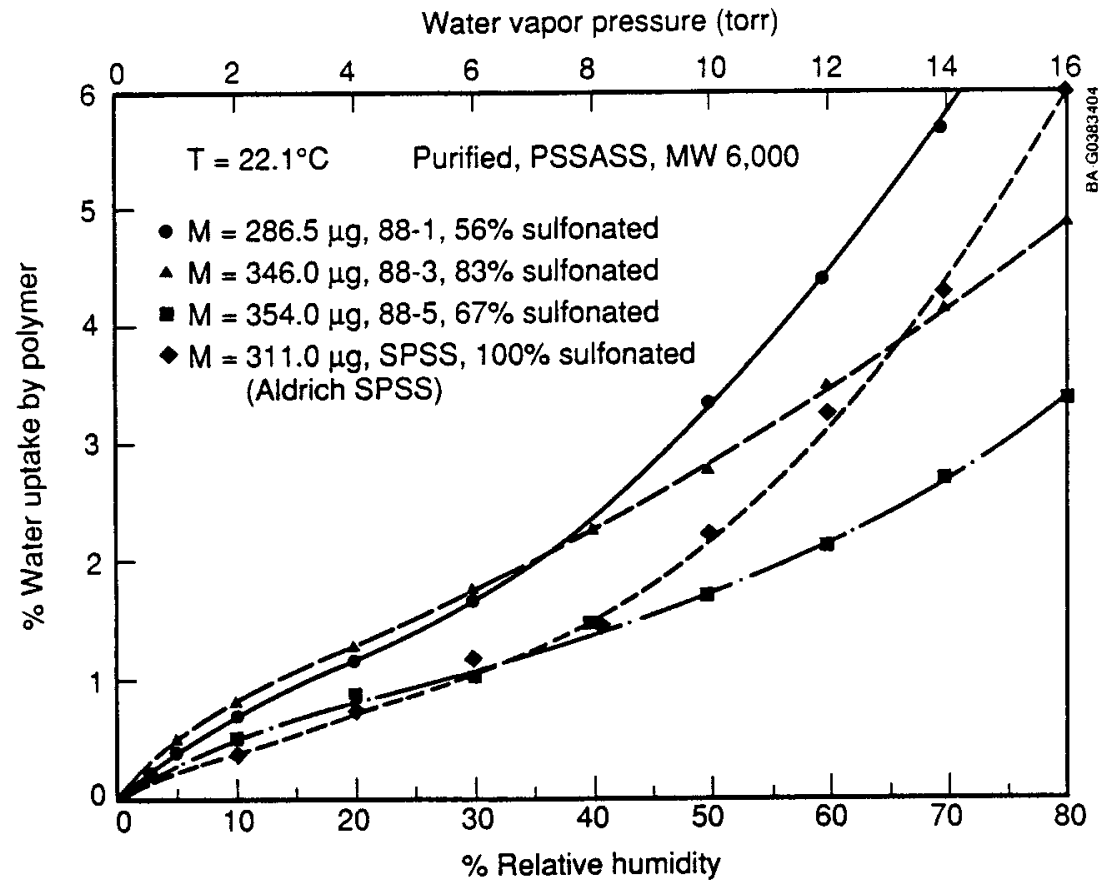

Figure 4-8. Water vapor adsorption isotherms at $22.1^{\circ} \mathrm{C}$ for SERI-prepared PSSASS (MW 6,000; purified) with different percent sulfonation compared with SPSS (1007 Aldrich Chemical)

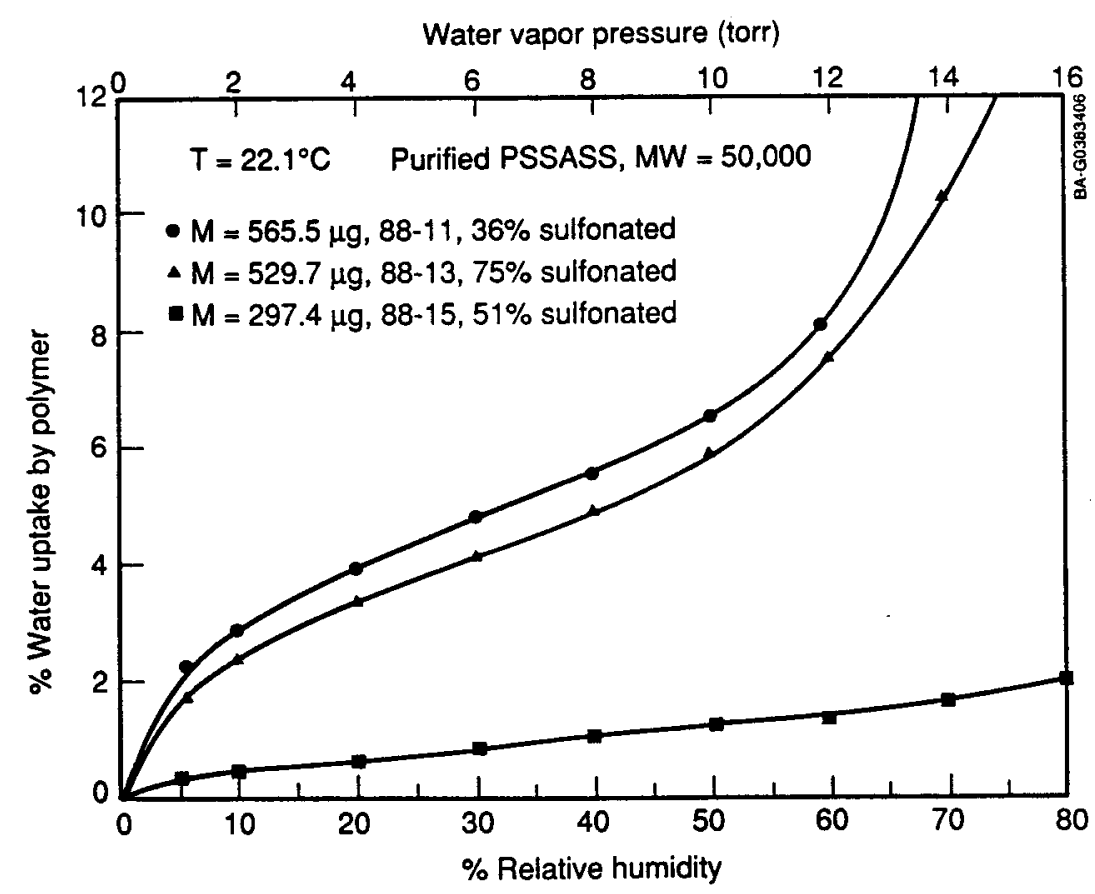

Figure 4-9. Water vapor adsorption isotherms at $22.1^{\circ} \mathrm{C}$ for SERI-prepared PSSASS (MW 50,000; purified) for different percent sulfonation 
point and a titration procedure adopted for preparing PSSASS samples as already discussed in Section 4.4 .

\subsubsection{Influence of PSSASS Retained in the Organic Solvent}

As a matter of interest, isotherms of PSSASS that are retained in the DCE solution also had low capacity and borderline BET Type 3 shapes (Figure 4-10). As expected, the PSSASS retained by this organic solvent is of little interest as an ADM.

\subsubsection{Influence of Cations (Counterions)}

At no time in our prior work had we determined isotherms of SERI-prepared PSSA. Three isotherms are shown in Figure 4-11 for freshly prepared PSSA with a MW of 6000 and $40 \%, 60 \%$, and $80 \%$ sulfonation. As seen, there are enormous capacity changes and desirable shapes are obtained (i.e., $40 \%$ sulfonation). These results for freshly prepared, unpurified, PSSA samples are potentially very significant. The isotherms for unpurified PSSA ( $M W=6,000$ ) show capacities of $20 \%, 120 \%$, and $400 \%$ at $50 \%$ R.H. The largest capacity we obtained on any desiccant polymer at $50 \%$ R.H. in all our prior work is $40 \%$ (PACM, Czanderna 1988). Furthermore, the shape and capacity of the $40 \%$ sulfonated PSSA are both very desirable for an ADM. Our principal caution is that these are data for one sample and the remarkable results must be repeated several

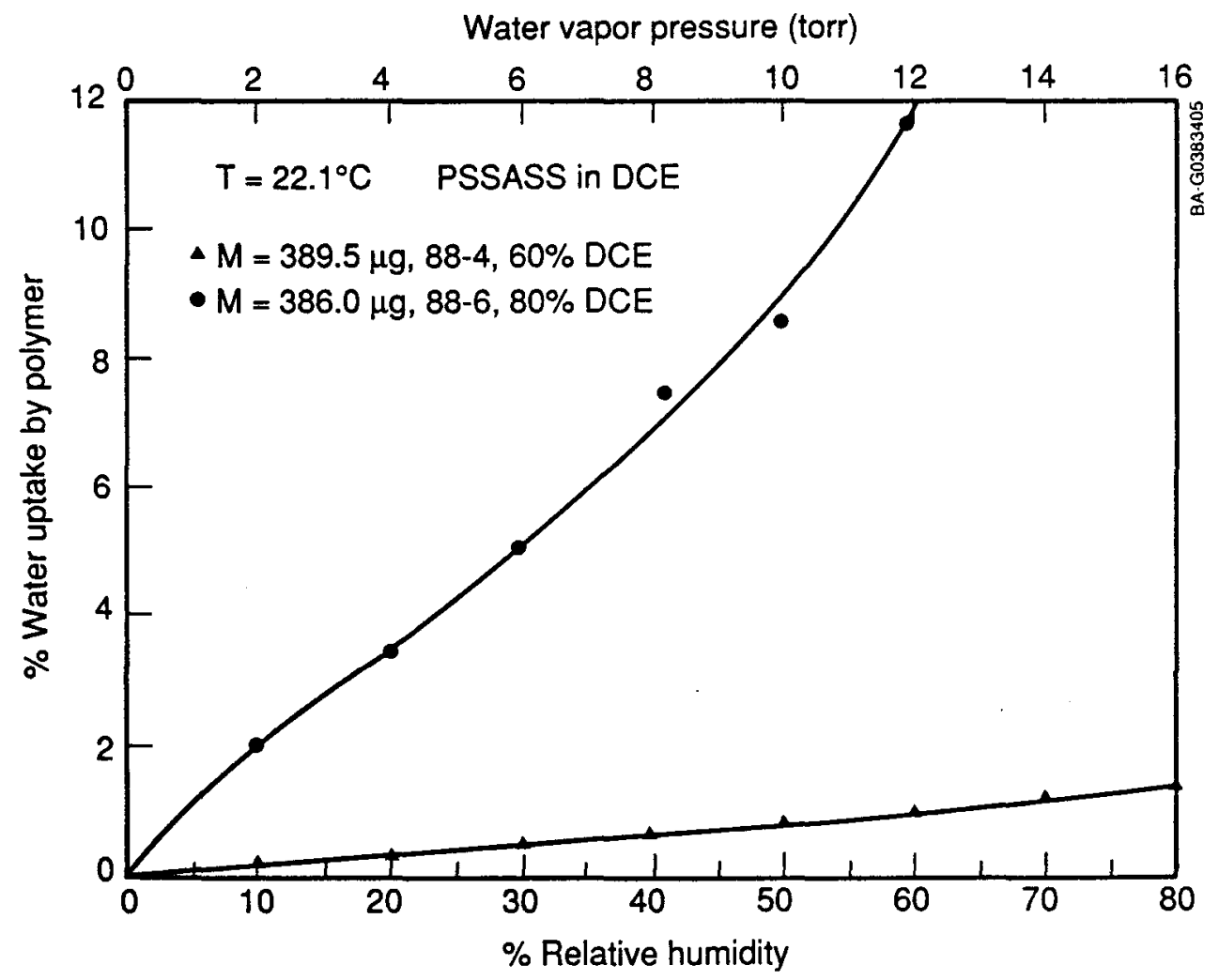

Figure 4-10. Waste vapor adsorption isotherms at $22.1^{\circ} \mathrm{C}$ for SERI-prepared PSSASS soluble in DCE for targeted sulfonations of $60 z$ and $80 \%$ 


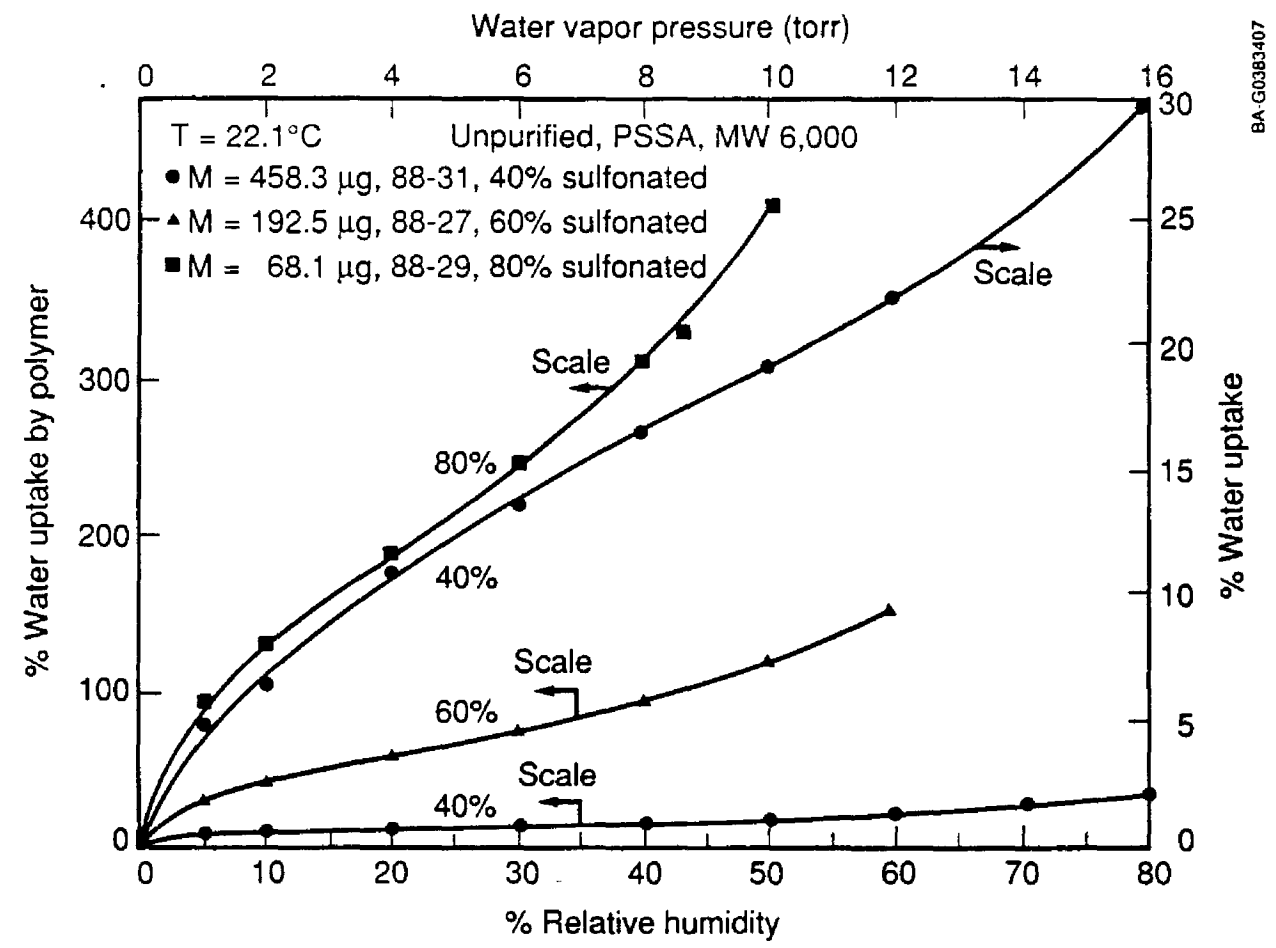

Figure 4-11. Water vapor adsorption isotherms at $22.1^{\circ} \mathrm{C}$ for SERI-prepared PSSA (MW 6,000; unpurified) for targeted sulfonations at 407,607 , and 807

times to ensure that we have indeed obtained a most significant result. In PSSA, $\mathrm{H}^{+}$is the counterion that interacts with the $\mathrm{SO}_{3}$ group. When the PSSA was titrated with $\mathrm{NaOH}$, the capacity decreased to the still respectable levels of $20 \%$ to $40 \%$ at $50 \%$ R.H. and the isotherms became BET Type 2 (Figure 4-6).

\subsection{Conclusions}

Our future work will emphasize using the titration method because of the better results obtained as well as its simplicity for preparing modifications of PSSASS. With different percentages of sulfonations of the initial PSSA, salts with different counterions can be readily formed by using different titrants. These should include $\mathrm{H}^{+}, \mathrm{Li}^{+}, \mathrm{K}^{+}, \mathrm{Cs}^{+}$, and then divalent and trivalent counterions. 


\subsection{SUMMARY OF CANDIDATE ADM AND MODIFIED POLYMERS}

Candidate ADM are those 1 isted in section 1.4. We have been able to modify the PSSASS and SPSS during the last year but did not have the resources to study any of the other candidate materials. Some improvements in the isotherm shape result by selecting a MW between 6,000 and 50,000 , but within this MW range there is not a pronounced influence on isotherm shape or capacity. The percent sulfonation can influence the capacity markedly and to a lesser extent the isotherm shape. The last modification of PSSA will be to form ionic salts with different cations than sodium. The dramatic sorption effect by PSSA was not expected based on our prior knowledge. We are optimistic that different cations attached to PSSA by the titration method will have the greatest influence on both capacity and isotherm shape. 


\subsection{OTHER RELATED ACTIVITIES}

\subsection{Isotherms of PSSASS Used by Cargocaire, Inc.}

The isotherms in Figure 4-4 were taken on the PSSASS that is being used in a collaborative effort between SERI and Cargocaire, Inc. They used Versa TL 501, which as can be seen, has the least desirable shape of nearly all the samples of PSSASS characterized in this work. However, Versa TL 501 is available in large quantities from the National Starch Company, and it still should provide reasonable results that demonstrate how polymers might function in a CDCS.

Five repeated kinetic studies were made for adsorption and desorption between 1 and 12 torr ( $5 \%$ and $60 \%$ R.H.). In all cases, adsorption was completed in less than 2 min and desorption completed in 3 to $4 \mathrm{~min}$. There were changes in the amount adsorbed during each cycle, with some evidence for stability in the fourth and fifth cycles. More cyclic stability studies are clearly needed.

\subsection{Isotherms of PSSASS, PAAAS, and CSSS Studied at SERI's Sorption Test Facility}

For studies planned by A. Pesaran and C. Bingham at the SERI Desiccant Sorption Test Facility, PAAAS and CSSS were obtained from other commercial sources. We obtained samples of their PAAAS and CSSS and measured the sorption isotherms, which are plotted in Figure 6-1. Both the capacity and shape of these are comparable to isotherms reported earlier for the sources listed in Table 3-1 (Czanderna 1988). However, isotherms of PSSASS are significantly poorer in both shape and capacity than those we have routinely measured from Polysciences, Inc., and Scientific Polymer Products, Inc.

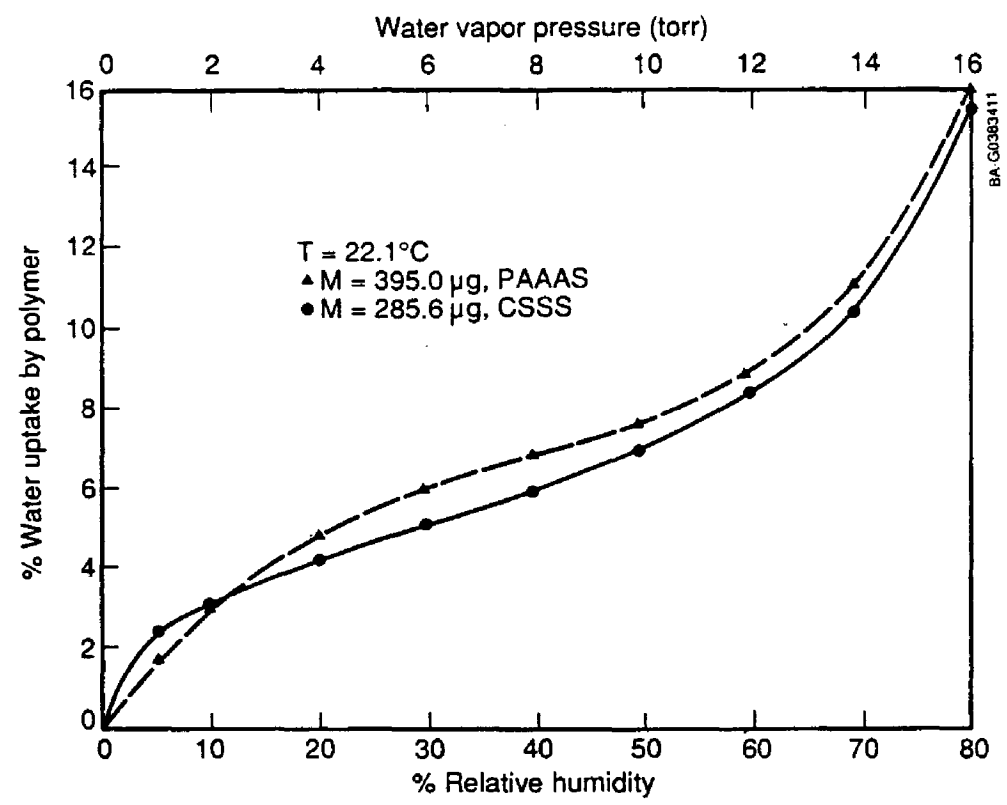

Figure 6-1. Water vapor adsorption isotherms at $22.1^{\circ} \mathrm{C}$ for commercial preparations of PAAAS and CSSS studied at the SERI sorption Test Facility 


\subsection{FUTURE ACTIVITIES}

As given in Section 1.6, the long-term technical approach for studying the water-vapor sorption by ADM for use in regenerative DCS includes conducting experimental work and interpreting the data to secure the necessary understanding. The following parts of the technical approach are particularly relevant for 1989 at the funding guidance indicated.

(1) Identify, select, rank, and prepare potential ADM for study;

(2) Determine the effect of chemical modification of candidate ADM and their surfaces on the sorption performance; and

(3) Modify polymeric materials to improve their sorption performance and synthesize new polymeric materials that are "molecularly engineered" to function as an "ideal" ADM.

For (1), the updated 1iterature search begun late in FY 1987 may be completed. We expect that about 10 potential candidate polymers will be identified, and these must be screened for their suitability as candidate ADM in the same manner as those discussed in Section 4.0. For (2), chemical modification of candidate polymers will continue, with an objective of improving the isotherm shape and sorption capacity without compromising the other desirable properties of the polymer. For ( 3 ), additional efforts to synthesize and modify polymeric materials with an objective of making an "ideal" ADM will be made. Both (2) and (3) require that additional personnel with polymer synthesis experience be added to the project.

The objectives for the ADM subtask during FY 1989 and 1 ater years, where the numbers in parentheses correspond to those in the technical approach given in Section 1.6 , are to:

(a) Modify optimal commercially available or prepared copolymers with "small and large" counterions $(2,8)$;

(b) Synthesize new, cross-linked, hydrophilic desiccant polymers (2);

(c) Investigate the potential of thermal- or light-triggered collapse phenomena of super hydrophilic polymers (2);

(d) Characterize all polymers prepared for their essential physical properties and functional group concentrations (6);

(e) Characterize the water sorption performance properties for all polymers prepared (6); and

(f) Investigate the isotherm shape at sorption temperatures between $10^{\circ}$ and $27^{\circ} \mathrm{C}(6)$, and at about $80^{\circ} \mathrm{C}$.

Items (11) and (12) in Section 1.6 will be continued, as needed, to complement the new work performed in (a) through ( $f$ ).

Major anticipated benefits that will accrue in the future from work in FY 1989 and beyond include: (1) identifying ADM that have the properties of or approaching the ideal desiccant; (2) evaluating several ADM in an engineering configuration through interactions with other projects funded by DOE, GRI, and private industry; and (3) establishing SERI as a primary center of quality 
assurance for characterizing the sorption performance of both inorganic and organic materials, independent of an engineering configuration. Characterization work on other SERI tasks could then reveal the sorption performance in an engineering configuration.

Depending on the funding levels, the work may also provide required information for items (7) through (10) in the technical approach, i.e., systematically modifying inorganic materials and characterizing them for sorption performance; studying the cyclic stability of candidate polymers after concluding initial sorption screening where real-time cyclic stability studies will be made to provide accelerated simulation of real-time use in a DCS; determining heats of adsorption for candidate materials; performing theory and computer simulation for diffusivity measurements for the geometry of a polymer on a QC or as a suspended film and comparing prediction with actual measurements; performing controlled studies to identify causes of sorption degradation induced by contaminants (e.g., silica gel, sorption, composition, bonding); and initiating studies to understand basic vapor-surface interactions between water and two or three candidate materials (sorption, bonding, surface composition, pore size, and so on).

The following activities are planned for FY 1989:

(1) Modify two commercially available or laboratory-prepared copolymers with one small and one large cation;

(2) Investigate the isotherm shape on two candidate polymers between $17^{\circ}$ and $27^{\circ} \mathrm{C}$;

(3) Synthesize one new, cross-1inked, hydrophilic desiccant polymer; and

(4) Complete a progress report (DOE deliverable). 


\subsection{REFERENCES}

Adamson, A. W., 1982, Physical Chemistry of Surfaces, 4th edition, New York: Wiley, pp. 537-539.

Aylward, N. N., 1975, J. Polym. Sci. Polym. Chem. Ed., Vol. 13, p. 373.

Barlow, R. S., December, 1982, Analysis of the Adsorption Process and of Desiccant Cooling Systems - A Pseudo-Steady-State Model for Coupled Heat and Mass Transfer, SERI/TR-631-1330, Golden, CO: Solar Energy Research Institute.

Bry-Air and Cargocaire, 1984, for example, manufacture air driers; American Solar King manufactures Sunaire. "Solar King's Cooling Gambit," Solar Age, October 1984, pp. 25-27.

Bulygin, A. N. et al., 1983, "Study of the Structure of Polymeric Sorbents," Polymer Sci., SSSR, Vol. 25, No. 3, pp. 1179-1187.

Butler, J. A. V., A. B. Robins, and K. V. Shooter, 1957, Proc. Royal Soc. Ser., Vol. A, No. 241, p. 299.

Carroll, W. R., and H. Eisenberg, 1966, J. Polym. Sci. Vol. A-2, No. 4, p. 599.

Collier, R. K., 1987, Florida Solar Energy Center, private communication.

Collier, R. K., R. S. Barlow, and F. H. Arnold, 1982, "An Overview of OpenCycle Desiccant Cooling Systems and Materials," J. Solar Energy Engr., Vol. 104, pp. 28-34.

Collier, R. K., T. S. Cale, and Z. Lavan, 1986, Advanced Desiccant Materials Assessment, GRI-86/0181, Final Report, Feb. 1985-May 1986, Chicago, IL: Gas Research Institute.

Czanderna, A. W., 1988, Polymers as Advanced Materials for Desiccant Applications: 1987, SERI/PR-255-3308, Golden, CO: Solar Energy Research Institute.

Czanderna, A. W., and T. M. Thomas, May 1986, Advanced Desiccant Materials Research, SERI/PR-255-2887, Golden, CO: Solar Energy Research Institute.

Czanderna, A. W., and T. M. Thomas, June 1987a, Advanced Desiccant Materials Research-1986, SERI/PR-255-3102, Golden, CO: Solar Energy Research Institute.

Czanderna, A. W., and T. M. Thomas, 1987b, "A Quartz Crystal Microbalance Apparatus for Water Sorption by Polymers," J. Vac. Sci. Technol., Vol. A5, pp. 2412-17.

Czanderna, A. W., and T. M. Thomas, October 1989, "Polymers: Options as Advanced Desiccant Materials," Conference Proceedings of a Workshop on Desiccant Cooling and Dehumidification Opportunities for Buildings, T. R. Penney, ed., SERI/CP-254-3000, Golden, CO: Solar Energy Research Institute.

Czanderna, A. W., and R. Vasofsky, 1982, "Surface Studies with the Vacuum U1tramicrobalance," Prog. Surface Sci., Vol. 9, No. 2, pp. 45-82. 
Czanderna, A. W., and S. P. Wolsky (eds.), 1980, Microweighing in Vacuum and Controlled Environments, Amsterdam: Elsevier.

Fraioli, A. V., March 1983, Investigation of Manganese Dioxide as an Improved Solid Desiccant, ANL-83-22, Argonne, IL: Argonne National Laboratory.

Gregg, S. J., and K. S. W. Sing, 1982, Adsorption, Surface Area, and Porosity, New York: Academic Press.

Jordan, D. O., T. Kurucsev, and M. L. Martin, 1969, Trans. Faraday Soc., Vol. 65, P. 606 .

Jurinak, S., 1982, Open Cycle Solid Desiccant Cooling Component Models and Simulations, Ph.D. dissertation, Madison, WI: University of Wisconsin.

Lu, C., and A. W. Czanderna (eds.), 1984, Applications of Piezoelectric Quartz Crystal Microbalance, Amsterdam: Elsevier.

Mita, K., T. Okubo, and N. Ise, 1976, J. Chem. Soc. Faraday Trans., Vol. 1, No. 72 , p. 504.

Parent, Y., 1985, Davison Division, W. R. Grace, private communication.

Pesaran, A. A., and A. F. Mills, February 1984, Modeling of Solid-Side Mass Transfer in Desiccant Particle Beds, SERI/TP-255-2170, Golden, CO: Solar Energy Research Institute.

Pesaran, A. A., T. M. Thomas, T. R. Penney, and A. W. Czanderna, September 1986, Methods to Quantify Contamination Effects on Silica Gel Samples, SERI/TR-252-2802, Golden, CO: Solar Energy Research Institute.

Roth, H. H., 1957, Ind. and Eng. Chem., Vol. 49, p. 1820.

Sauerbrey, G., 1959, Z. Physik, Vol. 155, p. 206.

Schlepp, D. R., and R. Barlow, September 1984, Performance of the SERI Parallel Passage Dehumidifier, SERI/TR-252-1951, Golden, CO: Solar Energy Research Institute.

Schlepp, D. R., and K. J. Schultz, September 1984, High Performance Solar Desiccant Cooling Systems, SERI/TR-252-2497, Golden, CO: Solar Energy Research Institute.

Szymczak, J., P. Holyk, and P. Ander, 1975, J. Phys, Chem. Vol. 79, p. 269. 


\section{APPENDIX A}

Project Summary (1985-1988)

\section{A.1 Research Scope}

\section{A.1.1 Scope/Background}

An advanced desiccant material (ADM) can advance solar buildings technology not only by lowering the cost of commercial solid desiccant cooling systems (DCS) to compete with conventional air-conditioning, but also by eliminating the need for adding peak-load generating capacity by electric utilities.

The optimum sorption properties of the desiccant materials in DCS were identified in a recent study of systems analysis (Collier, Cale, and Lavan, 1986). If an ideal desiccant can be identified, the coefficient of performance (COP) of a DCS can be improved from 0.85 to 1.05 (which can now be obtained with silica gel--the present industrial standard), up to 1.3 to 1.4 or close to the theoretical maximum. The COP is equal to the cooling capacity divided by the heat input (Collier, Barlow and Arnold 1982). At the same time, the cubic feet per minute per ton can be reduced from a range of 310 to 400 for silica gel to a range of 200 to 250 for an ideal desiccant. If both of these factors are achieved, DCS could be cost-competitive with other current air-conditioning systems, which is not possible for silica gel (Collier, Cale, and Lavan, 1986). Prior to their conclusions, SERI's ADM project was initiated to identify new low-cost, next-generation materials with the desired water vapor sorption performance, i.e., isotherm shape, sorption capacity, adsorption and desorption kinetics, and cyclic stability. of the commercially available inorganic (e.g., alumina gel, chromia gel, charcoal) and organic materials, over 25 commercially available polymeric materials have been selected as potential candidates for use in DCS. By considering the available polymeric desiccants, scientists note or have demonstrated that:

- Polymers have the potential of being modified so sorption isotherms of the desired shape and heats of adsorption of about $10.8 \mathrm{kcal} / \mathrm{mol}$ are both obtained.

- Polymers have been identified that sorb water from $5 \%$ to more than $80 \%$ of their own weight.

- Polymers have the potential for being readily fabricated into shapes for DCS, e.g., a honeycomb structure $10 \times 0.04 \times 0.06$ inches; when a "desiccant polymer" cannot be a structural material, it may be grafted onto a structural polymer.

- Polymer structures have the potential of being fabricated to provide high diffusivities of water vapor through the material, thus permitting sorption and desorption to be completed within a few minutes.

- Polymers can be regenerated at temperatures below $80^{\circ} \mathrm{C}$ for thermally desorbing water.

- Polymers have the potential for maintaining long-term stability through thousands of sorption-desorption cycles.

- Commercial polymers are available at less than $\$ 2 /$ pound or comparable to the cost of commercial-grade silica gel. 
Accordingly, polymeric materials could not only serve as both the desiccant and support structure in a desiccant wheel, but also could be replaced easily and inexpensively if their water sorption capacity degrades with time for any reason. Accordingly, the initial emphasis of this research has been to characterize the water sorption performance of polymeric materials that could serve in an economically competitive DCS.

\section{A.2 Scope/Statement of Work}

The Department of Energy has an interest in identifying next-generation, lowcost materials as advanced desiccants for solar cooling applications and to understand the role of surface phenomena on the performance of ADM. Research in this area may lead to new or modified materials, or both, that will improve the COP of DCS and provide a scientific understanding of the water vapor/ desiccant interactions to underpin the technological application of durable ADM. To accomplish the objectives of this research, the Solar Energy Research Institute (SERI) will:

(1) Identify, select, prioritize, and prepare potential ADM for study;

(2) Modify polymers and inorganic materials to improve their sorption performance and synthesize new polymeric materials that are "molecularly engineered" to function as an "ideal" ADM;

(3) Identify the performance criteria of ADM including sorption performance and durability;

(4) Identify the necessary measurements for characterizing the water-vapor sorption performance of potential ADM;

(5) Design, purchase, construct, install, and use experimental apparatus necessary for characterizing the sorption performance and establishing the durability of ADM;

(6) Measure the sorption performance and determine relevant physical parameters of potential ADM to establish which materials are candidate ADM based on the criteria in (3);

(7) Determine the repeatability of the sorption performance of candidate ADM from (1), (2), (3), (4), and (6) as a function of sorption-desorption cycles at time intervals corresponding to DCS;

(8) Determine the effect of chemical modification of ADM and ADM surfaces on the sorption performance;

(9) Conduct fundamental scientific investigations to understand the interplay among composition, bonding, topography, surface area, pore volume, pore size distribution, morphology, and their changes during cycling and use in real environments;

(10) Perform analytical and theoretical work, as needed, to assess the opportunities and limitations of candidate ADM for use in the engineering configurations of contemporary DCS;

(11) Cooperate with others performing desiccant research and development to expedite the testing of candidate ADM in engineering configurations; and

(12) Prepare reports and publications, and make presentations to disseminate the results of the work. 


\section{A.1.3 Objectives/Research Progress}

\section{A.1.3.1 Objectives}

The technological objective is to identify a next-generation, low-cost material with which solar radiation or heat from another low-cost energy source can be used for regenerating the water vapor sorption activity of the desiccant. The scientific objective of this task is to determine how the desired sorption performance of advanced desiccant materials can be predicted by understanding the role of their surface phenomena and the materials modifications.

\section{A.1.3.2 Research Progress}

Referring to the numbered items in Section A.1.2 "Scope/Statement of Work" and to references in Section A.3 "Bibliography," we have:

(1a) Completed a literature search (Czanderna and Thomas, May 1986), identified polymeric and inorganic materials as potential advanced desiccants (ibid.), prioritized them for study (ibid.), and prepared them for characterizing their sorption performance (Czanderna and Thomas, May 1986; June 1987; Czanderna, December 1988);

(1b) Developed in detail the opportunities for utilizing polymeric materials as ADM (Czanderna and Thomas, June 1987 and October 1989);

(2) Established the feasibility for synthesizing/modifying polymers as ADM (Czanderna and Neidlinger, December 1988);

(3a) Identified the key materials parameters for prioritizing potential ADM (Czanderna and Thomas, May 1986), ranked all identified materials of over 300 possibilities (ibid.);

(3b) Identified the water-vapor sorption performance criteria for narrowing the potential ADM to a few candidate ADM (Czanderna, December 1988). The sorption performance includes the sorption capacity from $5 \%$ to $60 \%$ R.H., isotherm shape, rate of adsorption and desorption, and cyclic stability of the ADM in water vapor;

(4) Identified microgravimetric, compositional surface analytical, infrared spectroscopic, scanning electron microscopic, and thermal gravimetric measurements as the minimum number of techniques necessary for studying desiccant materials and understanding their morphological and surface properties (Czanderna and Thomas, May 1986);

(5) Designed, purchased, assembled, constructed, installed, and used a quartz crystal microbalance (QCM) for characterizing the sorption performance of organic (polymeric) and inorganic materials (Czanderna and Thomas, June 1987; 1987; Czanderna, December 1988), and designed, assembled, and installed a Sartorius beam microbalance (SM) system for use on the project (Czanderna, December 1988; Czanderna and Neidlinger, December 1988);

(6a) Measured the sorption performance of over 23 potential commercially available polymeric ADM materials with the QCM (Czanderna and Thomas, May 1986; June 1987; 1987; October 1989; Czanderna, December 1988) and used the criteria in (2) to narrow the number to nine candidate 
ADM (Czanderna and Neidlinger, 1988). The measurements include determining sorption isotherms, rate of adsorption and desorption at each pressure increment or decrement, cyclic stability, and qualitative evaluations of permeation rates (Czanderna and Thomas, June 1987; 1987; Czanderna and Neidlinger, December 1988). Measurements of the heat of adsorption, pore volume, morphology, etc., for more detailed materials characterization have not been made.

(6b) Measured the sorption isotherms for commercially available polystyrene sulfonic acid sodium salt (PSSASS) and sodium polystyrene sulfonate (SPSS) for various molecular weights (MW), and for SERI-prepared modifications of polystyrene sulfonic acid (PSSA) and PSSASS with various MWs and degrees of sulfonation (Czanderna and Neidlinger, December 1988);

(6c) Designed an experimental procedure with an existing thermal gravimetric apparatus for studying the cyclic stability of ADM in humid air;

(6d) Demonstrated that surface compositional analysis using $X$-ray photoelectron spectroscopy and infrared spectroscopy will be useful for securing both fundamental and technological information about both present desiccant materials and ADMs;

(7) Initiated cyclic stability studies of several candidate polymeric ADM and established that nine polymers remain as serious candidate. ADM (Czanderna, December 1988); and

(8) Prepared proposals for securing the funding necessary to pursue issues (2) $-(11)$ in the statement of Work that have not been addressed or are only partially completed.

\section{A.2 Research History}

\section{A.2.1 Funding Levels for ADM Research (in K\$)}

Funding levels for ADM research are summarized below (given in $\mathrm{K} \$$ ).

\begin{tabular}{cccccc}
\hline & FY 1985 & FY 1986 & FY 1987 & FY 1988 & TOTAL \\
\hline Operating & 80 & 75 & 150 & 126 & 431 \\
Capital & $\frac{55}{135}$ & $\frac{\text { None }}{75}$ & $\frac{\text { None }}{150}$ & $\frac{\text { None }}{126}$ & $\frac{55}{486}$ \\
\hline
\end{tabular}

\section{A.2.2 Technical Problems and Solutions Achieved or Planned}

The planned solutions are identified in Section A.4, "Future Directions." From hundreds of potential commercially available polymeric desiccants, we have narrowed these to nine candidate ADM. A crucial problem for the future will be to synthesize polymeric materials with the properties tailored to the needs of an ADM. This effort has never been done, but should be realizable with a combined effort from a polymer scientist and continued characterization work. Clearly sorption performance characterization of ADM using beam microbalance techniques is needed. At the same time, the capital investment in SERI's QCM has resulted in a unique piece of apparatus that is now being 
copied by a number of industrial research laboratories as a result of work performed by Czanderna and Thomas (1987).

\section{A.3 Future Direction}

The long-term technical approach for studying the water-vapor sorption by ADM for use in regenerative DCS consists of carrying out experimental work and interpreting the data to secure the necessary understanding. The following variables are particularly relevant: (1) selection, preparation, and study of a particular material; (2) water-vapor sorption capacity and heat of adsorption by the solid desiccant; (3) rate of adsorption at about $22^{\circ} \mathrm{C}$ and of desorption at a modestly elevated $\mathrm{T}$; (4) repeatability of (2) and (3) as a function of cycles with short time intervals; (5) effect of chemical modification of the desiccant on (2)-(4); and (6) changes in the composition and topography of desiccant surfaces and the bonding of water vapor during cycling.

For pursuing the Statement of Work, we plan to continue using a QCM and initiate using an SM to obtain the water-sorption data required for (1)-(4). Specifically, we need to (a) systematically modify or synthesize polymers, or both, and characterize them for sorption performance; (b) continue sorption screening of polymers modified at SERI; (c) initiate using a SM to screen candidate polymers that cannot be studied with the QCM; (d) characterize sorption performance of SERI synthesized polymers; (e) complete the final sorption screening of nine candidate commercially available polymers; ( $f$ ) complete the final sorption screening of up to eight potential candidate commercially available polymers; ( $g$ ) study the cyclic stability of candidate polymers after concluding initial sorption screening where real-time cyclic stability studies will be made to provide accelerated simulation of real-time use in DCS; (h) systematically modify inorganic materials and characterize them for sorption performance; (i) determine heats of adsorption for candidate materials; (j) complete our efforts on a technique for studying inorganic powders (e.g., silica gel) with the QCM; (k) study inorganic materials and some polymers using the SM; (1) perform theory and computer simulation for diffusivity measurements for the geometry of a polymer on a quartz crystal and compare prediction with actual measurements; (m) perform controlled studies to identify causes of sorption degradation induced by contaminants (e.g., silica gel, sorption, composition, bonding); and $(n)$ initiate studies to understand basic vapor-surface interactions between water and two or three candidate materials (sorption, bonding, surface composition, pore'size, and so on).

The additions of $(c)$ and $(k)$ are especially attractive because SERI will have the means for being a center of quality assurance for characterizing the sorption performance of both inorganic and organic materials, independent of an engineering configuration. Characterization work on other SERI tasks could then reveal the sorption performance in an engineering configuration.

\section{A.4 Bibliography}

Collier, R. K., R. S. Barlow, and F. H. Arnold, 1982, "An Overview of OpenCycle Desiccant Cooling Systems and Materials," J. Solar Energy Engr., Vol. 104, pp. 28-34. 
Collier, R. K., T. S. Cale, and Z. Lavan, 1986, Advanced Dessicant Materials Assessment, GRI-86/0181, Final Report, Feb. 1985-May 1986, Chicago, IL: Gas Research Institute.

Czanderna, A. W., December 1988, Polymers as Advanced Materials for Desiccant Applications: 1987, SERI/PR-255-3308, Golden, CO: Solar Energy Research Institute.

Czanderna, A. W., and H. H. Neidlinger, December 1988, Polymers as Advanced Materials for Desiccant Applications: 1988, SERI/PR-255-3443, Golden, CO: Solar Energy Research Institute (draft).

Czanderna, A. W., and T. M. Thomas, May 1986, Advanced Desiccant Materials Research, SERI/PR-255-2887, Golden, CO: Solar Energy Research Institute. (Available from the National Technical Information Service, Springfield, VA 22161).

Czanderna, A. W., and T. M. Thomas, June 1987, Advanced Desiccant Materials Research: 1986, SERI/PR-255-3012, Golden, CO: Solar Energy Research Institute (available from the National Technical Information Service, Springfield, VA 22161).

Czanderna, A. W., and T. M. Thomas, 1987, A Quartz Crystal Microbalance Apparatus for Water Sorption by Polymers," J. Vac. Sci. Technol., Vol. A5, p. 2412 .

Czanderna, A. W., and T. M. Thomas, October 1989, "Polymers: Options as Advanced Desiccant Materials," Proceedings of a Workshop on Desiccant Cooling and Dehumidification Opportunities for Buildings, T. R. Penney, ed., SERI/CP-254-3000, Golden, CO: Solar Energy Research Institute. 


\section{APPENDIX B \\ Advanced Desiccant Materials and Desiccant Cooling Systems: Relationship and Background}

\section{B.1 Relationship of Desiccant Materials to Desiccant Cooling Systems}

Desiccant materials must have a favorable performance/cost ratio, provide satisfactory performance, and have cost-effective 1 ifetimes; widely available materials need to be certified, modified, or, in some cases, developed specifically for use in desiccant cooling systems (DCS). Some of the important parameters for the water solid-desiccant-material system include isotherm shape, sorption capacity, heat of sorption, rate of sorption at or near the desiccant bed temperature $\left(25^{\circ}-55^{\circ} \mathrm{C}\right)$, rate of desorption at an elevated temperature, physical and chemical stability of the desiccant, and cyclic repeatability of the sorption amount and rates. Some important conclusions and recommendations on these parameters were reached in the recent modeling study for regeneration at $160^{\circ} \mathrm{C}$ (Collier, Cale, and Lavan 1986), but the possibility of identifying new materials with optimal properties was not considered.

Except for recent work on this project and on manganese oxides (Fraioli 1983), most of the published work in the past decade has been on silica gels and zeo1ites. These materials have performance limitations (e.g., isotherm shape, large heat of adsorption, high regeneration temperatures, and hysteresis on cycling) that restrict their potential for use in DCS (Collier, Barlow, and Arnold 1982; Collier, Cale, and Lavan 1986). Therefore, a search for an advanced desiccant material (ADM) is a natural research need for enhancing the potential of deploying cost-effective DCS. These results led the Gas Research Institute (GRI) to initiate a multiyear desiccant materials research program in 1986; in 1987, it began supporting work on hydrate-type inorganic materials at LaRoche Chemicals Inc., proprietary organic formulations at the Eaton Corporation, and with others. No publications of the GRI-supported work have been made in the open literature.

\section{B.2 Background for Studies of ADM}

The arguments for desiccating water from air in an open-cycle DCS are wellknown (Collier, Barlow, and Arnold 1982). The principal limitations are related to finding a desiccant material with the required combination of sorption parameters, such as capacity, sorption heat, sorption rates at the bed temperature, desorption rate at a minimally elevated temperature, and cyclic stability. Other parameters or properties of interest have also been identified (Czanderna and Thomas 1986). These sorption parameters are connected with the energetics associated with gas-solid interactions (Gregg and Sing 1982; Czanderna and Vasofsky 1982).

A number of available inorganic porous solids have large internal surface areas and pore volume with an enormous affinity to sorb water. Some types of inorganic solids may sorb up to $40 \%$ of their weight and remain physically dry (Gregg and Sing 1982), which is desirable for DCS applications (Collier, Barlow, and Arnold 1982). Some organic polymers may sorb over 50\% of their weight (Bulygin et al., 1983; Czanderna and Thomas 1986); the uptake of water 
here is internal to the polymer, and, as with many porous solids, the dynamics of the sorption process is diffusion controlled.

The sorption of water vapor by the desiccant then is given by the reaction scheme:

$$
\begin{array}{ccc}
\mathrm{D}(\mathrm{s})+\mathrm{H}_{2} \mathrm{O}(\mathrm{v}) & \mathrm{D} \cdot \mathrm{H}_{2} \mathrm{O}_{\text {surface }} \\
\mathrm{D}(\mathrm{s})+\mathrm{D} \cdot \mathrm{H}_{2} \mathrm{O}_{\text {surface }} & \longrightarrow & \mathrm{D} \cdot \mathrm{H}_{2} \mathrm{O}_{\text {internal }}+\mathrm{D}(\mathrm{s}),
\end{array}
$$

where $D(s)$ is a solid desiccant adsorption site. Water vapor adsorbs onto the surface $[E q .(B-1)]$ and permeates into the solid by several possible diffusion processes [Eq. $(B-2)]$ to provide the total sorption. Empty surface sites are filled by further adsorption $[\mathrm{Eq} \cdot(\mathrm{B}-1)]$. Desorption of water vapor from the desiccant occurs by the reverse sequence

$$
\mathrm{D} \cdot \mathrm{H}_{2} \mathrm{O}_{\text {surface }} \longrightarrow \mathrm{D}(\mathrm{s})+\mathrm{H}_{2} \mathrm{O}(\mathrm{v})
$$

and

$$
D(s)_{\text {surface }}+\mathrm{D} \cdot \mathrm{H}_{2} \mathrm{O}_{\text {internal }} \longrightarrow \mathrm{D} \cdot \mathrm{H}_{2} \mathrm{O}_{\text {surface }}+\mathrm{D}(\mathrm{s})_{\text {internal }} \text {, }
$$

where empty surface sites are generated [Eq. (B-3)] by desorption and water sorbed in the material must first occupy a surface site [Eq. $(B-4)]$ before desorption via Eq. $(B-3)$.

Although the details of the molecular processes are much more complex than illustrated by Eqs. ( $B-1)$ through ( $B-4)$, they illustrate that the sorption capacity is gained by at least two kinetic steps involving the rate of adsorption [Eq. $(B-1)]$ and the rate of permeation into the solid [Eq. (B-2)]. Equations $(B-3)$ and $(B-4)$ illustrate the reverse steps of desorption and diffusion. The adsorption and desorption rates are usually much faster than the permeation and diffusion rates. The permeation (diffusion) steps provide the "solid-side" resistance in the sorption-regeneration sequence. The principal limitations are related to finding a desiccant material with the required combination of isotherm shape, sorption capacity, sorption heat, sorption rates at the bed temperature, desorption rate at a minimally elevated temperature, cyclic stability of the sorption properties, and stability of the desiccant itself. These parameters are connected with the energetics and kinetics associated with gas-solid interactions.

The forces primarily responsible for the sorption processes arise from interactions of the electric field at the surface of the solid/adsorbate molecules, which is water for solid desiccants. Because of its large dipole moment and polarizability, the water molecule produces a large heat of adsorption. The total interaction between the water molecules and the adsorbent surface contains contributions from several types of interactions such as dipole-dipole, dipole-quadrupole, and dipole-induced dipole. Since water is a polar molecule and the sorption sites are primarily ionic, it appears conceivable that the electric field at the surface could be modified by introducing different ions or functional groups at the surface, thus changing the heat of adsorption. On inorganic surfaces, modifications could be done by ion exchange techniques and during the preparation of organic materials. The modifications can also 
influence the sorption capacity and isotherm shape, so the desired material must have the optimal combination of capacity and adsorbate-binding energy.

From sorption isotherms, the bimding energy of the water adsorbate to the solid can be determined. The rate of diffusion through the porous material can be calculated, and, in principle, the rate of desorption from the solid can be determined and compared with experimental results. The latter must be taken on materials that at least approach the configurations used for the calculations. Practically, the sorption rate processes will be reduced by pore volume diffusion and intraparticle diffusion in a packed bed of particles. Although some sorption data are available in the literature (Gregg and sing 1982) for candidate desiccant adsorbent materials, these data have not been analytically scrutinized to determine the suitability of new materials in advanced desiccant applications.

Recent articles show both experimental activity in water-vapor adsorbent systems and analysis of the associated phenomena (Czanderna and Thomas 1986). In most of these studies, the conventional volumetric, scanning electron microscopic, and electron microscopic techniques used provide only a limited understanding of fundamental processes. Surface compositional analyses of solids have not been correlated with changes in sorption behavior. Bonding information available from infrared spectroscopy has been coupled with adsorbed amounts in only a few papers. The quartz crystal microbalance (QCM) has not been used extensively to obtain adsorption equilibrium and rates (Czanderna and Thomas 1986). The great potential of the QCM is being exploited for both screening and evaluating advanced polymeric desiccant materials for this research.

To understand the molecular processes for water-solid adsorbent desiccant systems, there is an obvious opportunity to combine using QCM, infrared, and surface spectroscopies to correlate rates and amount sorbed with the chemical bonds formed (related to heats of adsorption) and surface composition (effects of chemical modification). Furthermore, any changes in the amount sorbed and rate of desorption should result in changes in the bonding at the surface (infrared). Finally, experimental data in the literature are not sufficient for assessing the potential of polymeric materials as desiccants. The objectives of this research have been developed from the obvious unexplored opportunities for providing scientific understanding or information about candidate water-desiccant materials and rationale for modifications of the adsorbents that might be necessary.

\section{B.3 Bibliography}

Bulygin, A. N. et al., 1983, "Study of the Structure of Polymeric Sorbents," Polymer Sci., SSSR, Vol. 25, No. 3, PP. 1179-1187.

Collier, R. K., R. S. Barlow, and F. H. Arnold, 1982, "An Overview of OpenCycle Desiccant Cooling Systems and Materials," J. Solar Energy Engr., Vo1. 104, pp. 28-34.

Collier, R. K., T. S. Cale, and Z. Lavan, 1986, Advanced Desiccant Materials Assessment, GRI-86/0181, Final Report, Feb. 1985-May 1986, Chicago, IL: Gas Research Institute. 
Czanderna, A. W., and T. M. Thomas, May 1986, Advanced Desiccant Materials Research, SERI/PR-255-2887, Golden, CO: Solar Energy Research Institute.

Czanderna, A. W., and R. Vasofsky, 1982, "Surface Studies with the Vacuum Ultramicrobalance," Prog. Surface Sci., Vol. 9, No. 2, pp. 45-82.

Fraioli, A. V., March 1983, Investigation of Manganese Dioxide as an Improved Solid Desiccant, ANL-83-22, Argonne, IL: Argonne National Laboratory.

Gregg, S. J., and K. S. W. Sing, 1982, Adsorption, Surface Area, and Porosity, New York: Academic Press. 


\author{
APPENDIX C \\ Criteria for Identifying Potential \\ and Candidate Advanced Desiccant Materials
}

In 1985, about 300 articles were identified in a literature search for potential candidate advanced desiccant materials (ADM). Since the sorption capacity of a desiccant is critical for its use in desiccant cooling systems (DCS), the computerized literature search was carried out for articles containing the words "water vapor" and "polymers." About one-half of the 1 iterature citations were articles written in Japanese, Russian, or Eastern Bloc languages; these were not translated based on our best judgments from the English abstracts. In late FY 1987, the literature search was updated; about 70 additional publications concerning potential polymeric ADM were identified. Nearly all of these publications are in foreign languages, especially Japanese and Russian. Copies of the articles have been or are being secured and translations will be obtained where appropriate.

\title{
C.1 Criteria Used for Ranking Potential Candidate Materials
}

Two sets of parameters could be applied for ranking the identified materials in a list of potential candidate ADM. The first set is: (1) cost, both initial and life cycle; (2) performance; (3) durability, lifetime, and how performance parameters depend on temperature; (4) availability; (5) processibility; (6) modifiability; (7) stability at temperatures below $100^{\circ} \mathrm{C}$; and (8) specific heat. For polymeric materials, the most important initial criterion is (2). As a first approximation, polymers should have relatively uniformly good prospects for (1), (4), (5), (6), and (7), and marginal values for ( 8 ). It was not expected that durability of polymers used as desiccants [i.e., (3)] would have been evaluated, and this expectation is correct (Czanderna and Thomas 1986).

The second set of parameters considered are performance related and were divided into three categories: primary, secondary, and other criteria. These criteria were ranked and reviewed by several members of the Solar Energy Research Institute (SERI) desiccant team before they analyzed the available literature references. The criteria, which are more detailed than previous listings, were generated by SERI researchers in 1985 (Czanderna and Thomas 1986). These now must be modified because of a recent computer parametric study (Collier 1987). The modified criteria listed below are subjectively based on a combination of input obtained by the task leader from several sources, including verbal communications with K. Collier, GRI program managers, Kaiser personnel, Eaton personnel, J. Mitche11, D. Ruthven, and SERI task team members. The revised criteria are listed below with brief explanatory statements.

Primary criteria for further narrowing the potential of polymeric materials as advanced desiccants are as follows:

(a) Isotherm shape (Type 1 moderate as defined by Collier, Cale, Lavan 1986). Silica gel has a linear-type isotherm, which results in an upper 1 imit of 1.05 for the thermal coefficient of performance (COP). 
(b) Capacity change of at least $6 \%-8 \%$ by weight between $5 \%$ and $60 \%$ relative humidity (R.H.). Large capacities are not nearly as important as previously thought, which not only enlarges the list of polymeric potential ADM, but also of inorganic materials as well.

(c) Rapid adsorption at $22^{\circ} \mathrm{C}$. "Rapid" means that most of the capacity change must be completed in less than $5 \mathrm{~min}$ to correspond to the anticipated exposure time in rotary commercial desiccant cooling systems (CDSC).

(d) Reversibility on desorption at $22^{\circ} \mathrm{C}$ for isotherm determination. Rapid desorption rates are helpful but not necessary because the desorption kinetics will be increased by elevated regeneration temperatures.

(e) Reproducibility in (a)-(d) above following regeneration up to $80^{\circ} \mathrm{C}$; i.e., the present anticipated regeneration temperature for solar-based DCS. If higher regeneration temperatures are planned, then the $80^{\circ} \mathrm{C}$ must be increased accordingly.

Secondary criteria that will be applied to materials passing (a)-(e) include:

(f) Diffusivity of greater than $10^{-9} \mathrm{~m}^{2} / \mathrm{s}$. Qualitative aspects of diffusivity or permeation rates are automatically observed during studies with quartz crystal microbalance (QCM) and Sartorius beam microbalance (SM) techniques from (c) and (d).

(g) Desorption rates of water at the regeneration temperature that provide sufficient capacity change in less than $5 \mathrm{~min}$.

(h) Heats of adsorption at or near $10.8 \mathrm{kcal} / \mathrm{mol}$, which is the latent heat of vaporization of water. Higher heats of adsorption result in a decrease in overall DCS efficiencies.

(i) Specific heats with $(\mathrm{dw} / \mathrm{dx}) / \mathrm{C}_{\mathrm{p}}$ greater than $0.5 \mathrm{gK} / \mathrm{J}$ for $5 \%$ to $80 \% \mathrm{R} . \mathrm{H}$. This parameter is now thought ${ }^{\mathrm{P}}$ to be less important than in 1985 , and in fact, does not have a wide range of variability for polymers.

Other criteria, which then need to be applied to materials that remain candidates after applying (a) - (i), include cyclic stability, durability in pure water, synthetic-air environments, and 1 ife-cycle costs that are competitive, with or without contamination by use in working environments.

Since the goal of our research is to measure the performance parameters of the material itself, the obvious engineering-related parameters (e.g., bed geometry, material form, desiccant size and shape, packing density, pressure drops, and heat and mass transfer) were not considered, but could easily be factored into future concepts.

\section{C.2 Bibliography}

Collier, R. K., 1987, Florida Solar Energy Center, private communication.

Collier, R. K., T. S. Cale, and Z. Lavan, 1986, Advanced Desiccant Materials Assessment, GRI-86/0181, Final Report, Feb. 1985-May 1986, Chicago, IL: Gas Research Institute.

Czanderna, A. W., and T. M. Thomas, May 1986, Advanced Desiccant Materials Research, SERI/PR-255-2887, Golden, CO: Solar Energy Research Institute. 


\section{APPENDIX D}

Desiccant Compositions for Desiccant Cooling Systems

A. W. Czanderna and Solar Energy Research Institute (SERI) General Counsel Patent Application, July 8, 1988

A copy of this document is available upon written request to A.W. Czanderna at SERI. The request will be honored when counsel determines it is appropriate. 


\author{
APPENDIX E \\ Quartz Crystal Microbalance Apparatus
}

\title{
E.1 Background
}

The commonly known quartz crystal microbalance (QCM) is actually a piezoelectric quartz crystal (QC) resonator mounted in an appropriate holder. Piezoelectric materials are used extensively as electromechanical transducers and as highly stable oscillators for frequency control. For the latter application, mechanical and thermal stabilities are more important, and materials such as alpha quartz have been found to be valuable. Quartz has the smallest coefficient of the widely used crystalline solids, but the material can still be used in oscillator circuits to secure $\mathrm{pg} / \mathrm{cm}^{2}$ mass sensitivities. The effect of mass added to the frequency of a quartz oscillator has been used since the early days of radio, when frequency adjustment was accomplished by a pencil mark on the crystal.

It was established early that the cut (i.e., the orientation of the QC plate with respect to the crystallographic axes) had an important effect on the resonance frequency. For use as a piezoelectric crystal detector, only AT- or BT-cut quartz plates are useful. These crystals are two high-frequency mode plates that vibrate in a shear mode about an axis parallel to the major surface; these plates have low or zero temperature coefficients at the temperature of use, and have surfaces that are antinodal in displacement. The temperature coefficients are a critical function of the angle of cut. The AT-cut is superior in temperature coefficient and in mass sensitivity. The crystals used most frequently are $10-$ to $16-\mathrm{mm}$ disks, squares, or rectangles that are approximately $0.19 \mathrm{~mm}$ thick. The metal electrodes are 300 to $1000 \mathrm{~nm}$ thick; 3 to $8 \mathrm{~mm}$ in diameter; and made of gold, nickel, silver, or aluminum. The frequency of the QC depends on the physical dimensions of the quartz plate and on the thickness of electrodes placed on it. The resonant frequency of a crystal is normally obtained using a frequency meter attached to the output of an oscillator circuit (Czanderna and Thomas 1986).

Using an idealized model, a relationship was developed (Sauerbrey 1959) between the mass of metal films deposited on QC and the change in frequency. The relationship, which was derived for quartz (AT-cut) crystals vibrating in the thickness shear mode, is

$$
\Delta f=-2.3 \times 10^{-6} \mathrm{f}^{2} \Delta \mathrm{m} / \mathrm{A},
$$

where $\Delta f$ is the change in frequency due to the coating ( $\mathrm{Hz})$, $f$ is the frequency of the quartz plate $(\mathrm{MHz}), \Delta \mathrm{m}$ is the mass of deposited coating $(\mathrm{g})$, and $A$ is the area coated $\left(\mathrm{cm}^{2}\right)$. The constant includes the density of quartz and the velocity of a wave in the shear mode. Equation (E-1) predicts that a commercially available 6-MHz crystal, which has been chosen in this research, would have a mass sensitivity of about $12 \mathrm{ng} / \mathrm{Hz}$ for a coated area of $1 \mathrm{~cm}^{2}$. The sensitivity factor for crystals used in our research is actually $14 \mathrm{ng} / \mathrm{Hz}$. 


\section{E.2. QC Operation}

If a desiccant material with an overall density of $1.4 \mathrm{~g} / \mathrm{cm}^{3}$ is placed on a QC, then a desiccant film $0.1 \mu \mathrm{m}$ thick with an area of $1 \mathrm{~cm}^{2}$ would have a mass of $14 \mathrm{\mu g}$, so the limit of detectability of mass change would be $0.01 \% / \mathrm{Hz}$ $[100 \% \times(14 \mathrm{ng} / \mathrm{Hz}) / 14 \mathrm{\mu g}]$, where $\pm 0.1 \mathrm{~Hz}$ can be routinely monitored with our commercially available oscillator circuits. For thicker desiccant films, the percent mass sensitivity is even smaller. Since the interest is for desiccants with percent mass gains in water of over $5 \%$, the QCM sensitivity is more than sufficient, even if an active QC area of only $0.25 \mathrm{~cm}^{2}$ is used. The mass measuring range of the QCM will permit studying polymer thicknesses that vary by more than 100 times, so permeation rates can also be deduced.

For operation in a vacuum, the $Q C$ holder is an integral part of a vacuum system apparatus (as shown in Section 2; Figure 2-2 Czanderna and Thomas, 1986). The essential components of this holder include a 2.75-in. stainless steel Conflat ${ }^{8}$ vacuum flange with feedthroughs for a thermocouple, cooling water, and the electrical leads needed for operating the oscillator. The essential components of the vacuum system include a source of pure water vapor, capacitance manometer, valves for manipulating gas pressures, pumps, and low-pressure gauges. Sample temperatures are measured with thermocouples. Detailed descriptions of the QCM and vacuum chamber components are available (Czanderna and Thomas 1986).

The advantages of the QCM for measuring the sorption of water vapor by ADM are as follows:

- The fundamental water sorption properties of desiccant materials can be studied in the absence of any engineering design restrictions.

- An appropriate mass sensitivity $\left(14 \mathrm{ng} / \mathrm{Hz} \mathrm{cm}{ }^{2}\right)$ is obtained using commercially available equipment. For example, a $100 \mathrm{~nm}-t h i c k$ polymer film with a mass of $14 \mathrm{ng}$ on a $1-\mathrm{cm}^{2}$ QCM results in detectable mass changes of $0.01 \%$, or $10 \%$ of a single monolayer of an adsorbed gas is detectable for contaminant studies. (A precision of $\pm 0.1 \mathrm{~Hz}$ is obtained with our QCM.)

- The response time is fast (i.e., 2 s/point).

- It can be used in pure water vapor at pressures comparable to the relative humidity in actual desiccant systems. Thus, the sorption kinetics of the desiccant can be studied in the absence of any gas-side diffusion effects.

- It is simple to use and is not sensitive to shock or vibration.

- An accuracy of $<2 \%$ can be achieved.

- It can be easily adapted for simultaneous use with infrared or surface analysis equipment.

Some of the principal limitations of the QCM are the following:

- Samples must be coated onto the QC and must adhere to it, which presents a particular challenge when studying particulate materials.

- Only one temperature (or a narrow temperature range) can be studied with a given crystal at the maximum sensitivity.

- Liquid samples are not easily studied. 
- Condensation of unknown gases on the sample or volatile materials in the sample may cause problems in securing the actual water sorption.

\section{E.3 Bibliography}

Czanderna, A. W., and T. M. Thomas, May 1986, Advanced Desiccant Materials Research, SERI/PR-255-2887, Golden, CO: Solar Energy Research Institute.

Sauerbrey, G., 1959, Z. Physik, Vol. 155, p. 206. 


\section{APPENDIX F \\ Rinetic and Cyclic Stability Studies}

\section{F.1 Rinetics of Sorption and Desorption by Candidate Advanced Desiccant Material Polymers}

After each pressure increment or decrement while obtaining the isotherm data, the approach to the equilibrium mass gain or loss was recorded at 2-min intervals through the first $20 \mathrm{~min}$, and then at $10-, 20-$, or $30-\mathrm{min}$ intervals for 4 to $6 \mathrm{~h}$. In the semiautomatic operational mode of the quartz crystal microbalance (QCM), these data are printed but are not plotted for visual display or interfaced to a graphics terminal. Thus, all sorption-desorption kinetic curves must be plotted manually or evaluated by inspecting the printout of the data. The latter was chosen, and qualitative statements of fast, intermediate, and slow are assigned after visual inspection of the data. The definitions are as follows: fast, over $90 \%$ of the incremental or decremental mass change occurred in the first $10 \mathrm{~min}$; intermediate, over $90 \%$ of the mass incremental or decremental change occurred in the first $60 \mathrm{~min}$; and slow, less than $90 \%$ of the incremental or decremental mass change occurred during the first $60 \mathrm{~min}$. For commercial desiccant cooling system (CDCS), only fast kinetics will qualify a material as a candidate advanced desiccant material (ADM). Intermediate kinetics do not necessarily disqualify a material as a candidate, and slow kinetics probably disqualify a material.

To illustrate the type of data that can be retrieved for the materials listed in a prior report (Czanderna 1988, Tables 4-1 and 5-1), plots of the sorption and desorption kinetics were shown in Figures 5-22 and 5-23 of the report for several different polymers after increasing the water-vapor pressure from $5 \%$, $30 \%$, or $60 \%$ relative humidity (R.H.), or decreasing it from $60 \%$ or $80 \%$ R.H. These curves show that the kinetics are fast at all pressures. Similar data are archived in several thousand pages of printer output secured while measuring the isotherms. The data for the candidate polymeric materials listed in Section 1.4 are especially important for planning future experiments and for potential technological use of these polymers as ADM.

\section{F.2 Cyclic Stability studies}

As discussed in Appendix $C$, a candidate ADM must exhibit reproducible sorption behavior after being subjected to several tens of thousands of adsorption and desorption cycles. From our study of the literature, major changes in the sorption behavior of many polymers occur in the first one or two cycles. Repeated measurements of sorption isotherms have not been undertaken in previous work given in the literature or in this research. We have subjected several polymers to three to nine sorption cycles by simply remeasuring the isotherms. Typical results for the cyclic adsorption and desorption of water vapor are shown (Czanderna 1988) for sodium polystyrene sulfonate (SPSS), polyacrylic acid ammonium salt (PAAAs), and cellulose sulfate sodium salt (CSSS) in Figures 5-24 through 5-29 for the first three cycles. The cyclic reproducibility is excellent for the first three cycles. In contrast, similar adsorption data obtained for four cycles of polyethylene oxide (PEO) show a dramatic change in adsorption behavior from the first to second cycle, and continuing changes for the next two cycles. The changes quite likely result 
from physical processes occurring within the polymer because of the adsorption and desorption cycles.

\section{F.3 Bibliography}

Czanderna, A. W., 1988, Polymers as Advanced Materials for Desiccant Applications: 1987, SERI/PR-255-3308, Golden, CO: Solar Energy Research Institute. 


\section{APPENDIX G \\ Additional Classes of Polymers Identified in 1987 as Potential Advanced Desiccant Materials}

- Ionic salts of polystyrene sulfonic acid

- Ionic salts of polyacrylic acids

- Ionic salts of cellulose

- Cationic size/charge effects in ionic salts (e.g., $\mathrm{Li}^{+}, \mathrm{K}^{+}, \mathrm{Cs}^{+}, \mathrm{Mg}^{++}, \mathrm{Al}^{+++}$ versus $\mathrm{Na}^{+}$) 


\section{DISTRIBUTION LIST}

Mr. Carl Bergt

Trane Systems Engineering Co. 6200 Troup Highway

Tyler, TX 75711

Mr. Steve Brickley

Cargocaire Engineering Corp. 79 Monroe St.

Amesbury, MA 01913

Mr. Glen Chinery

Tennessee Valley Authority

217 Power Board B1dg.

Chattanooga, TN 37401

Mr. James Coellner

320 Walnut St. Suite 105

Philadelphia, PA 19106

Mr. Barry Cohen

Thermal Products Division

ThermoElectron Corporation

45 First Avenue

Waltham, MA 02154

Dr. K. Collier

Florida Solar Energy Center

300 State Road 401

Cape Canaveral, FL 32920

Mr. Michael Epstein

Fauske \& Associates, Inc. 162070 West 83rd Street

Burr Ridge, IL 60521

Dr. P. Fairey

Florida Solar Energy Center

300 State Road 401

Cape Canaveral, FL 32920

Mr. A. Hunter Fanney

National Institute of Standards

B1dg. 226, Room B310

Washington, DC 20234

Mr. Stephen D. Fitch

Bry-Air

P.0. Box 795

Sunbury, $\mathrm{OH} 43074$
Mr. Robert Goff

3M Corporation

Bldg. 224-2S-25, 3M Center

St. Paul, MN 55144-1000

Dr. John C. Goldsmith

U.S. Department of Energy

CE-421, Room 5H-047

1000 Independence Ave., S.W.

Washington, DC 20585

Mr. William C. Griffiths

Midland Ross Corporation

P.0. Box 791

New Brunswick, NJ 08903

Dr. R. Harkins

ASES

203017 th St.

Boulder, CO 80302

Mr. Robert J. Hassett

U.S. Department of Energy

CE-421, Room 5H-047

1000 Independence Ave., S.W.

Washington, DC 20585

Mr. Jim Hill

National Institute of Science and Technology

Technology B-148

Gaithersburg, MD 20899

Dr. Anthony Hines

1010 Engineering Building

University of Columbia

Columbia, MO 65211

Mr. Douglas Hittle

Colorado State University

Solar Energy Applications Lab

Fort Collins, CO 80523

Dr. Bruce Hunn

University of Texas at Austin

Balcones Research Center

10100 Burnet Road

Austin, TX 78758 
Ms. Mary Margaret Jenior

CE-421, RoOm 5H-047/FORS

U.S. Department of Energy

1000 Independence Avenue, S.W.

Washington, D.C. 20585

Mr. Theodore E. Kapus

Director

Office of Building Energy Research CE-42

U.S. Department of Energy

1000 Independence Ave., S.W.

Washington, DC 20585

Mr. Douglas Kosar

Gas Research Institute

8600 West Bryn Mawr Avenue

Chicago, IL 60631

Mr. Ted L. Kurkowski

U.S. Department of Energy

CE-30.1, Room 6C-026

1000 Independence Ave., S.W.

Washington, DC 20585

Dr. Zalman Lavan

Department of Mechanical Engineering

Illinois Institute of Technology

Center

Chicago, IL 60616

Dr. George Löf

Colorado State University

Solar Energy Applications Lab

Fort Collins, CO 80523

Dr. Ian Maclaine-cross

University of New South Wales

School of Mechanical and Industrial Engineering

P.O. Box 1

Kensington, NSW 2033 AUSTRALIA

Dr. John P. Millhone

CE-40, Room 5E-080

U.S. Department of Energy

1000 Independence Avenue, S.W.

Washington, DC 20585

Dr. J. Mitchell

University of Wisconsin-Madison

Engineer. Rsch. Bldg. 1341

1500 Johnson Drive

Madison, WI 53706
Janet Neville

U.S. Department of Energy

San Francisco Operations Office

1333 Broadway

Oakland, CA 94612

Olaf Nifontoff

150 Washburn Lane

Stony Pt., NY 10980

Mr. Davor Novosel

Gas Research Institute

8600 West Bryn Mawr Avenue

Chicago, IL 60631

Mr. Bryan Pardo

Director R\&E

American Solar King Corp.

700 Loop 340 South

Waco, TX 76710

Dr. Yves 0. Parent

Resident Engineer

Industrial Chemicals Research

Davison Chemical Division

W.R. Grace \& Co.

Washington Research Center

7379 Route 32

Columbia, MD 21044

Mr. Neil Patterson

Director of Integrated System

The Trane Company

3600 Pammel Circle

Lacrosse, WI 54601

Prof. D.M. Ruthven

University of New Brunswick

P.0. Box 4400

Fredericton, N.B.

CANADA E58 5A3

Mr. M.P. Scofield

CE-421

Building Systems and Materials

Division

U.S. Department of Energy

1000 Independence Ave., S.W.

Washington, DC 20585

Mr. William Seaton

ASHRAE

1791 Tullie Circle, N.E.

Atlanta, GA 30329 
Mr. Scott Sklar

Solar Energy Industries Association 1730 North Lynn Street

Suite 610

Arlington, VA 22209-2009

Mr. James A. Smith

Director

CE-421

Building Systems and Materials

Division

U.S. Department of Energy

1000 Independence Ave., S.W.

Washington, DC 20585

Mr. Samuel J. Taylor

CE-421

Building Systems and Materials

Division

U.S. Department of Energy

1000 Independence Ave., S.W.

Washington, DC 20585
M. Wahlig

Lawrence Berkeley Laboratories

University of California

1 Cyclotron Drive

Berkeley, CA 94720

$\mathrm{Mr}$. Alex Willman

A Cargocaire Resource and Management Foundation

1015 15th Street, N.W.

Washington, DC 20005

\section{SERI Distribution}

Dr. R. Anderson, 2540

Dr. L. Flowers, 2500

Dr. L.L. Kazmerski, 2130

Dr. M.L. Murphy, 2500

Dr. T. Penney, 2540 (3)

Dr. A. Pesaran, 2540 (3)

Dr. T. Potter, 2500

Ms. N. Reece, 220

Dr. R. Stokes, 2000

Dr. J.L. Stone, 2100

Author (20) 


\begin{tabular}{|c|c|c|c|}
\hline $\begin{array}{l}\text { Document Control } \\
\text { Page }\end{array}$ & $\begin{array}{l}\text { 1. SERI Repor No. } \\
\text { SERI/PR-255-3443 }\end{array}$ & $\begin{array}{l}\text { 2. NTIS Accession No. } \\
\text { DE90000385 }\end{array}$ & 3. Recipient's Accession No. \\
\hline \multirow{3}{*}{\multicolumn{3}{|c|}{$\begin{array}{l}\text { 4. Title and Subutle } \\
\text { Polymers as Advanced Materials for Desiccant } \\
\text { Applications: } 1988\end{array}$}} & \multirow{2}{*}{$\begin{array}{l}\text { 5. Publication Date } \\
\text { September } 1989\end{array}$} \\
\hline & & & \\
\hline & & & 6. \\
\hline \multicolumn{3}{|c|}{$\begin{array}{l}\text { 7. Author(s) } \\
\text { A.W. Czanderna, H.H. Neidlinger }\end{array}$} & 8. Pertorming Organization Rept. No. \\
\hline \multirow{2}{*}{\multicolumn{3}{|c|}{$\begin{array}{l}\text { 9. Performing Organization Name and Address } \\
\text { Solar Energy Research Institute } \\
1617 \text { Cole Boulevard } \\
\text { Golden, Colorado } 80401-3393\end{array}$}} & 10. Project/Task/Work Unit No. \\
\hline & & & $\begin{array}{l}\text { 11. Contract (C) or Grant (G) No. } \\
\text { (C) } \\
\text { (G) }\end{array}$ \\
\hline \multirow{2}{*}{\multicolumn{3}{|c|}{ 12. Sponsoring Organization Name and Address }} & $\begin{array}{l}\text { 13. Type of Report \& Period Covered } \\
\text { Progress Report }\end{array}$ \\
\hline & & & 14. \\
\hline \multicolumn{4}{|l|}{ 15. Supplementary Notes } \\
\hline \multicolumn{4}{|c|}{ 16. Abstract (Limit: 200 words) } \\
\hline \multicolumn{4}{|c|}{$\begin{array}{l}\text { This report documents work to identify a next-generation, low-cost material with which solar energy or heat } \\
\text { from another low-cost energy source can be used for regenerating the water vapor sorption activity of the } \\
\text { desiccant. The objective of the work is to determine how the desired sorption performance of advanced } \\
\text { desiccant materials can be predicted by understanding the role of the material modifications and material } \\
\text { surfaces. The work concentrates on solid materials to be used for desiccant cooling systems and which } \\
\text { process water vapor in an atmosphere to produce cooling. The work involved preparing modifications of } \\
\text { polystyrene sulfonic acid sodium salt, synthesizing a hydrogel, and evaluating the sorption performances of } \\
\text { these and similar commercially available polymeric materials; all materials were studied for their potential } \\
\text { application in solid commercial desiccant cooling systems. Background information is also provided on } \\
\text { desiccant cooling systems and the role of a desiccant material within such a system, and it includes the use } \\
\text { of polymers as desiccant materials. }\end{array}$} \\
\hline \multicolumn{4}{|c|}{$\begin{array}{l}\text { 17. Document Analysis } \\
\text { a. Descriptors Solar energy ; ma } \\
\text { b. Identifiers/Open-Ended Terms }\end{array}$} \\
\hline \multicolumn{4}{|c|}{ c. UC Categories 231} \\
\hline \multicolumn{3}{|l|}{ 18. Availability Statement } & 19. No. of Pages \\
\hline \multicolumn{3}{|c|}{$\begin{array}{l}\text { National Technical Information Service } \\
5285 \text { Port Royal Road } \\
\text { Springfield, Virginia } 22161\end{array}$} & 71 \\
\hline Springfield, V & ginia 22161 & & $\begin{array}{r}\text { 20. Price } \\
\text { A04 }\end{array}$ \\
\hline
\end{tabular}

